This item was submitted to Loughborough's Research Repository by the author.

Items in Figshare are protected by copyright, with all rights reserved, unless otherwise indicated.

\title{
Parental involvement in neonatal critical care decision-making
}

PLEASE CITE THE PUBLISHED VERSION

http://dx.doi.org/10.1111/1467-9566.12455

PUBLISHER

(c) Wiley

VERSION

AM (Accepted Manuscript)

PUBLISHER STATEMENT

This work is made available according to the conditions of the Creative Commons Attribution-NonCommercialNoDerivatives 4.0 International (CC BY-NC-ND 4.0) licence. Full details of this licence are available at: https://creativecommons.org/licenses/by-nc-nd/4.0/

\section{LICENCE}

CC BY-NC-ND 4.0

\section{REPOSITORY RECORD}

Shaw, Chloe, Elizabeth Stokoe, Katie Gallagher, Narendra Aladangady, and Neil Marlow. 2016. "Parental Involvement in Neonatal Critical Care Decision-making". Loughborough University.

https://hdl.handle.net/2134/21133. 


\title{
Parental involvement in neonatal critical care decision-making
}

\author{
Chloe Shaw ${ }^{1}$, Elizabeth Stokoe ${ }^{2}$, Katie Gallagher ${ }^{1}$, Narendra Aladangady ${ }^{3,4}$, Neil Marlow ${ }^{1}$ \\ 1: UCL Elizabeth Garrett Anderson Institute for Women's Health, University College London, London, UK \\ 2: Department of Social Sciences, Loughborough University, Loughborough \\ 3: Neonatal Unit, Homerton University Hospital, London \\ 4: Centre for Paediatrics, Barts and the London School of Medicine and Dentistry, QMUL \\ *Corresponding author \\ Chloe Shaw \\ Research Associate \\ UCL Elizabeth Garrett Anderson Institute for Women's Health \\ University College London \\ Rockefeller Building \\ 21 University Street \\ London \\ WC1E 6DE \\ UK \\ Tel: 02076796036 \\ Email: chloe.shaw@ucl.ac.uk
}

Acknowledgments: We are most grateful to the parents and doctors who allowed us to record and analyse these private conversations. We would like to thank members of the Discourse and Rhetoric Group at Loughborough for their comments in data sessions, with particular thanks to Paul Drew for his guidance in a number of sessions. Funding: National Institute of Health Research (NIHR) Programme Development Grant RG-DG-0611-10006. The Department of Health and NIHR had no role in the preparation, review or approval of the manuscript, and the decision to submit for publication.

\section{In press, Sociology of Health and Illness, April 2016}

\section{'Parental involvement in neonatal critical care decision-making': Highlights}

- We explore neonatal end-of-life decision making between parents and doctors.

- We developed detailed transcripts of real life conversations.

- Conversation analysis was used to analyse the decision making process.

- Two practices that doctors use to initiate decisions were identified.

- The analysis reveals the implications of these practices for parental involvement. 


\title{
Parental involvement in neonatal critical care decision-making
}

\author{
ABSTRACT \\ The paper analyses the decision-making process between doctors and parents of babies in \\ neonatal intensive care. In particular, it focuses on cases in which the decision concerns the \\ redirection of care from full intensive care to palliative care at the end of life. Thirty one \\ families were recruited from a neonatal intensive care unit in England and their formal \\ interactions with the doctor recorded. The conversations were transcribed and analysed using \\ conversation analysis. Analysis focused on sequences in which decisions about the \\ redirection of care were initiated and progressed. Two distinct communicative approaches to \\ decision-making were used by doctors: 'making recommendations' and 'providing options.' \\ Different trajectories for parental involvement in decision-making were afforded by each \\ design, as well as differences in terms of the alignments, or conflicts, between doctors and \\ parents. 'Making recommendations' led to misalignment and reduced opportunities for \\ questions and collaboration; 'providing options' led to an aligned approach with \\ opportunities for questions and fuller participation in the decision-making process. The \\ findings are discussed in the context of clinical uncertainty, moral responsibility and the \\ implications for medical communication training and guidance.
}

Keywords: Neonatal, End-of-life, Critical Care, Decision-Making, Ethics, Parents, Involvement, Conversation Analysis 


\section{INTRODUCTION}

Having a newborn baby cared for on a neonatal intensive care unit is a difficult time for parents. For some, this becomes particularly painful when they are faced with decisions around whether or not to continue life-sustaining treatment. Despite improvements in neonatal survival and outcome, death is still relatively common in perinatal medicine (ONS 2011). Stillbirths aside, a large proportion of perinatal deaths arise because of a decision to limit treatment for a baby who is suffering with serious complications after birth or following a period of intensive care in the neonatal unit. The majority of deaths $(60-80 \%)$ in neonatal intensive care are 'planned' (CEMACH 2009); that is, a decision is made to redirect care from intensive to 'supportive' or 'palliative' care, usually because of statistical probabilities around survival and severe long term morbidity (Costeloe, Hennessy et al. 2012).

Professional organisations such as the General Medical Council (GMC) and the Royal College of Paediatric and Child Health (RCPCH) state that decisions to redirect care should be centred on the 'best interests' of the baby, requiring consideration beyond the clinical context, to that of the family situation as a whole. These organisations recommend that parents should be involved in and share these critical care conversations and decisions. In the UK, the National Health Service Toolkit for high quality neonatal services recommends that "Clinical care decisions, including end-of-life decisions, are made by experienced staff in partnership with the parents and discussions held in an appropriate setting" (DoH, 2009:46). In this paper, we investigate what happens when consultants and parents talk about these decisions, and show how different ways of initiating decision-making communication have an immediate impact on the alignment, or otherwise, between parties as they decide what actions to take. The implications of our findings, for training doctors to have more effective and collaborative conversations with parents, will be discussed at the end of the paper. 


\section{Neonatal decision-making}

Despite national recommendations about shared decision-making, parents in a recent survey of neonatal units throughout the UK reported less than optimal involvement in the decision making process (Poppy 2009). Many parents report being distressed by insensitive communication and overwhelmed by conflicting information, suggesting that parent-doctor communication could be improved. This research highlights a need to explore the decisionmaking process in its empirical reality, both to understand what actually happens and, ultimately, to inform training of the health care professionals involved in this process.

The extent to which parents report, retrospectively, that they want to be involved in decision-making varies (Gillam and Sullivan 2011), although most parents report a wish to have some 'involvement' in the decision-making process. What this means is unclear, however, as it can range from awareness of a decision being made to actually making the final decision, collaboratively with the doctors or independently (Einarsdottir 2009; Caeymaex, Speranza et al. 2011; Rosenthal and Nolan 2013). Entering the decision-making conversation at different stages of its trajectory (e.g., following a medical decision that is then presented to the parents), may result in parents' differing perceptions of who ultimately made the decision about their infants treatment (McHaffie, Laing et al. 2001). These issues may be further complicated by feelings of responsibility and blame that might be being managed through these retrospective accounts. Despite national recommendations to guide the health care professionals involved in the decision-making process, many doctors are unaware of how to implement this guidance in practice (Duffy and Reynolds, 2011) and their personal opinions towards parental involvement and the continuation of treatment of the infant may differ. The impact of this can be seen through regional variations in infant outcomes of mortality and morbidity across resource-rich settings within the UK and throughout Europe. 
Whilst the research can highlight the differing perspectives of each party involved in neonatal decision-making, what remains unknown is what this process looks like in practice. What does 'involvement' actually mean and how is it achieved? If doctors are to be trained to have effective encounters with parents, what should go into that training? These questions remain largely unanswered, and so the current paper will address them via the analysis of actual encounters between doctors and parents.

By analysing real-time encounters, our approach contrasts with research to date on parent-doctor communication in the neonatal ICU. A number of previous studies adopt an ethnographic approach to evaluate the process of decision-making, observing and describing conversations but not analysing them directly. For example, Coeckelbergh and Mesman (2007) examined how parents and doctors describe imagined scenarios of what life would be like for the baby, to facilitate moral reasoning for decision-making. These imagined scenarios are considered theoretically by the authors as a tool for creating consensus and shaping action in a broad sense. What is not considered, however, is how they function within actual decision-making, in terms of the implications for the moment-by-moment involvement of parents. In another study, Vermeulen (2004) provides a detailed account of the decisions being made in a Dutch NICU. Parents were considered to be involved in decision-making through the presentation of facts by the doctors that enabled exploration of parental perspectives. While this provides insight into parental involvement in a broad sense, it does not provide a systematic analysis of the conversational implications of, say, informationgiving. Similarly, Orfali (2004) compared French and American NICUs, which, she argued, have contrasting ideological models of decision-making: parental autonomy in the United States, and paternalism in France. In French NICUs, doctors used the results of MRI scans and objective indices such as 'lesions greater than $2 \mathrm{~cm}$ ', to objectify a severe outcome and medical certainty, in situations where alternative outcomes might actually be possible. In 
contrast to the declared ideology, paternalism was still prevalent in USA NICUs, manifested as doctors not offering treatment limitations when this could be considered an appropriate option. The study identified important factors used in decision-making in the two countries: the criteria for considering redirection of care and whether parental 'permission' is sought. But the actual conversations between parents and doctors was not presented or analysed.

Three further studies get us closer to these actual conversations. Anspach's (1993) ethnographic study explored parental involvement in end-of-life decisions as an interactive process. She identified how parental assent (rather than informed consent) was achieved through reference to a united expert authority in which uncertainty and options were actively limited by doctors. Furthermore, by describing the baby's enduring suffering, should intensive care be continued, the doctors invoked "a moral precept with which most parents would find it hard to disagree" (Anspach, 1993: 98). Two recent studies (Boss et al, 2016; de Vos et al, 2015) examine recordings of doctor-parent conversation, but code and/or quantify a limited range of communicative behaviours, such as the distribution of talk or the number of parents' questions. What we do not get to see is how talk is distributed, or what types of questions get asked, leaving their impact on doctor-parent (mis)alignment unfolding inside an analytic 'black box' (Stokoe, 2010). The current study builds on this small body of work, opening up this 'black box', to the best of our knowledge, for the first time.

\section{Medical shared decision-making}

Outside the specifics of neonatal care, shared decision-making has received substantial attention across primary care (Elwyn, Edwards et al. 2001), paediatrics (Lipstein, Dodds et al. 2014), psychiatry (Goossensen, Zijlstra et al. 2007), cancer (Butow, Juraskova et al. 2010), multiple sclerosis (Pietrolongo, Giordano et al. 2013), and end-of-life care (Roter, Larson et al. 2000). Researchers have attempted to assess the extent and outcomes of patient 
involvement in decision-making through patient satisfaction measures, to determine the patients' perspective on this process.

Recordings of live medical encounters are frequently used to assess the uniformity of an intervention and enhance recall when eliciting patient views, as well as being analysed in their own right for features of shared decision-making. In the latter case, however, coding systems, used to measure the decision making process, are typically developed from theoretical perspectives around decision-making, as well as patient and health care professional perceptions. Although coding enables retrospective identification of aspects of talk that might be regarded as important, less attention is paid to the social organization of decision-making conversations.

Conversation analysts, in contrast, have demonstrated the importance of analysing actions such as 'decision-making' (alongside questioning, advising, offering, etc.) within the interactional context in which they are produced, rather than attaching pre-determined significance to them (Heritage and Maynard 2006). While some medical studies have taken a more inductive, descriptive approach to analysing decision-making (Gwyn and Elwyn 1999), conversation analysis goes further still, analysing conversational practices in terms of their situated use and interactional import, often changing what we think we know about how such interaction works. Conversation analysts have examined decision-making across many contexts including antenatal screening (Pilnick and Zayts 2012), paediatrics (Stivers 2005), primary care (Koenig 2011), diabetes (Koenig, Wingard et al. 2014), orthopaedic surgery (Clark and Hudak 2011), oncology (Collins, Drew et al. 2005), psychiatry (Quirk, Chaplin et al. 2012), and neurology (Toerien, Shaw et al. 2013).

This work has highlighted some of the practices through which patients' co-construct decisions through their responses to treatment recommendations. For example, Costello and Roberts (2001) showed that patients' weak agreements and silences help shape the final 
recommendation as something more aligned to the patients' perspective (see also Koenig, 2011). Ekberg and LeCouteur (2014) showed that, in cognitive behavioural therapy sessions, information-soliciting questions may co-implicate the client in decision-making by inviting a suggestion in the next turn rather than a more minimal acceptance or rejection. Toerien et al. (2013) showed how, in neurology treatment, 'option-listing' works better than making 'proposals' to open up a slot for patients to specify a preference. Within paediatric primary care encounters, Stivers (2005) found that affirmative recommendations for a treatment other than antibiotics are less likely to be followed by resistance than for a recommendation against antibiotic treatment. Finally, in antenatal consultations with community midwives, Pilnick (2008) showed how despite a clear orientation by the midwives to invoke shared decisionmaking around a newly introduced nuchal translucency screening programme, the way that the programme was presented did not actually provide this optionality in the interaction. For example, the programme was presented following the presentation of routine tests and so it had the potential of becoming normalized, with the decision itself being given less weight. These studies explicate the practices through which particular sub-types of decisionmaking initiations have implications for what happens next. The aim of our paper is to explore, using conversation analysis, the process of shared decision-making in the neonatal unit. Our work adds to the above body of knowledge by extending it to a novel context, and also by considering the implications for communication guidance and training by identifying effective and less effective practices. 


\section{DATA AND METHOD}

\section{Participants and characteristics}

Thirty one families were recruited from a single neonatal intensive care unit in England from July 2013 to April 2014. Families were recruited whose babies were critically ill and where a discussion around the redirection of care was a possibility in the future. The baby's consultant introduced the study to potential parents, all of whom had capacity to provide and give informed consent. Participation involved digitally recording all formal conversations between the neonatal team and the parents regarding the treatment of the infant. From the 31 families recruited, we identified 16 conversations (nine families; six consultants) in which specific conversations about the redirection of care occurred (from full intensive care to palliative care). Within these, there were five discussions about withdrawal of ongoing lifesupport, including mechanical ventilation; eight discussions about withholding treatment, where the child is not receiving life support but is at risk of deteriorating (and if agreed treatment would not be escalated), and eight discussions around 'do not resuscitate orders', that is, withholding formal resuscitation (such as adrenaline and chest compressions) should the baby acutely deteriorate (RCPCH 2004). Some conversations may have included more than one decision; for example, a decision around withholding or withdrawal of treatment as well as a 'do not resuscitate order', culminating in 21 sequences across the 16 conversations. The key clinical conditions for the sample included: one threatened preterm delivery of twins at 23 weeks gestation (one baby with the no amniotic sac); three infants with severe perinatal asphyxia; four infants born extremely preterm ( $<27$ weeks gestation) with neurological complications; and one infant born with a lethal congenital anomaly. Parents were from mixed ethnic and religious backgrounds: three families were White Caucasian, one 
Bangladeshi, three were black African, Caribbean or other, and for one, ethnicity was not recorded in the clinical notes; four were Christian, one Muslim and for three, religion was not recorded.

\section{Ethics}

The study received approval from the XXXX Research Ethics Committee and Research and Development approval from the participating NHS Trust. Parents and consultants gave written informed consent for their conversations to be recorded for research purposes; names and identifying details have been replaced with pseudonyms. The study was funded by XXXX. The funding body played no part in the conception, design, analysis or preparation of research outputs.

\section{Procedure}

For participating families, the attending doctor was asked to record all conversations that took place in the side room/parents' room, to ensure the privacy of the recording, while targeting those formal conversations where critical care decision-making was likely to arise. The recordings were captured using an audio digital recorder and securely stored using encrypted storage devices. While we acknowledge that aspects of the embodied interaction are unavailable for analysis, consent was constrained to audio rather than video recordings. This limitation will be addressed in future data collection where possible. Of the 16 conversations identified, the consultation lasted for 34 minutes on average (range 9 to 67 minutes), and comprised 8 hours 35 minutes in total. Such a dataset presents issues for analysis. While many CA studies focus on short one-to-one telephone calls, others, like ours, analyse long 
multiparty interactions. We present key extracts from lengthy and complex spates of conversation alongside an explanation of the context of the conversation to aid the reader with the analysis.

\section{Analytic method}

The recordings were analysed using the analytic method of conversation analysis (CA). The underlying principle of CA is that talk is organised in terms of social action (Drew 2005). Whether this be requesting, advising, complaining or complimenting (etc.), turns at talk build actions and make relevant next actions. CA explicates the patterned ways in which these actions work, and which constitute the ordered and finessed way in which members of a culture communicate with and understand one another (Drew 2005). Turns at talk are analysed within the sequential context in which they are produced and their implications for how the sequence unfolds. By recording and analysing naturally occurring conversations, CA provides a method for understanding the 'black box' of what actually happens in encounters, rather than in simulations, role-play or post-hoc accounts.

\section{Analytic procedure}

Recordings were transcribed using the Jefferson (2004) transcription system which captures how talk is delivered, including emphasis and pitch movement, volume and temporal placement (Hepburn and Bolden 2012). Capturing these details enables analysts to pin down precisely when encounters are progressing smoothly and when there are difficulties, which is particularly important in workplace and institutional encounters when one is attempting to identify, say, the relative effectiveness of one question design over another, one way of 
explaining a service over another (see Stokoe, 2013). Decision-making sequences were analysed in terms of the implications for what participants are able to do next.

\section{ANALYSIS}

Doctors initiated decision-making sequences in two main ways: 1) 'making recommendations', in which they refer to discussions within their medical team and invoke 'the best interests' of the baby, and 2) 'providing options', in which they not only list different possible courses of action, but also employ other features such as deferring decisions to provide opportunity for contemplation. We will show the different trajectories afforded by each sub-type, particularly in terms of subsequent opportunities for parents to ask questions and the affiliative nature of those questions. Table 1 below shows the incidence of these two approaches in the data, as well the form of parent response, which will be discussed later.

Table 1: Summary of decision format and subsequent expression of preference

\begin{tabular}{|l|c|c|c|c|c|}
\hline & \multicolumn{3}{|c|}{ Expression of preference } & \multirow{2}{*}{ Total } \\
\cline { 2 - 6 } & $\begin{array}{c}\text { Freely done } \\
\text { with } \\
\text { minimal } \\
\text { resistance }\end{array}$ & $\begin{array}{c}\text { Deferred by } \\
\text { doctor } \\
\text { Recceptance }\end{array}$ & $\begin{array}{c}\text { Strong } \\
\text { resistance }\end{array}$ & 9 \\
\hline Recommendations & 1 & 0 & $\begin{array}{c}4 \\
\text { (1 including deferral by parents) }\end{array}$ & 4 & 6 \\
\hline Presenting options & 4 & 2 & 0 & 0 & 9 \\
\hline
\end{tabular}




\section{Making recommendations}

We present a collection of extracts where the decision point is initiated by a strong recommendation for a single course of action regarding the continuation or discontinuation of life-sustaining treatment. The extracts exemplify the common features for building recommendations and for the response options that recommendations afford. As discussed earlier, all names presented within the results are pseudonyms. In Extract 1, the consultant (Dr) has just informed Mum (M) of her baby Nathaniel's genetic test results and the outcome of the cardiac multidisciplinary team meeting. Nathanial has a condition similar to Trisomy 18 and an associated cardiac condition. The decision was not to undergo heart surgery because of a likely poor outcome for Nathanial. We join the conversation following the delivery of this news and the decision to be made is regarding the withholding of ventilator support if Nathaniel stops breathing.

\section{Extract 1: F1R3, Part A (1-38)}

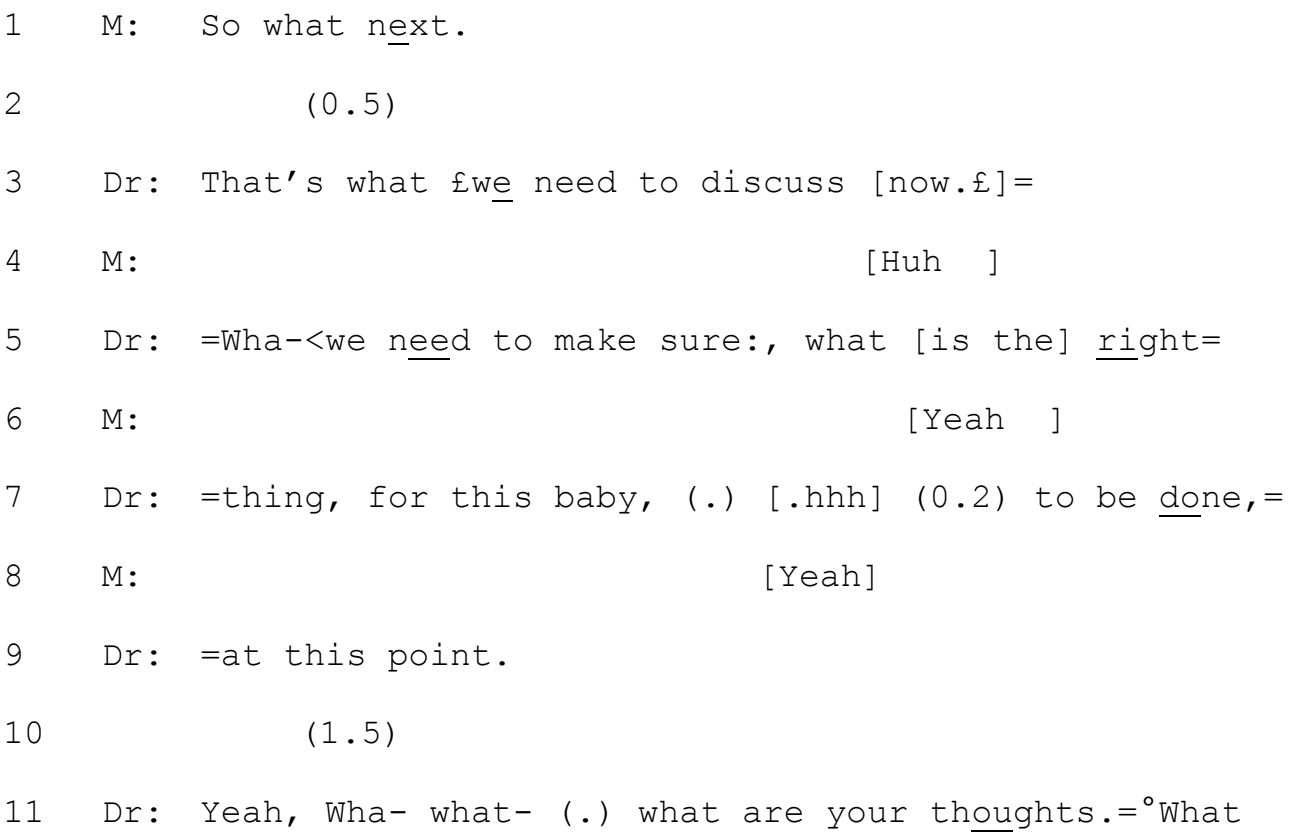




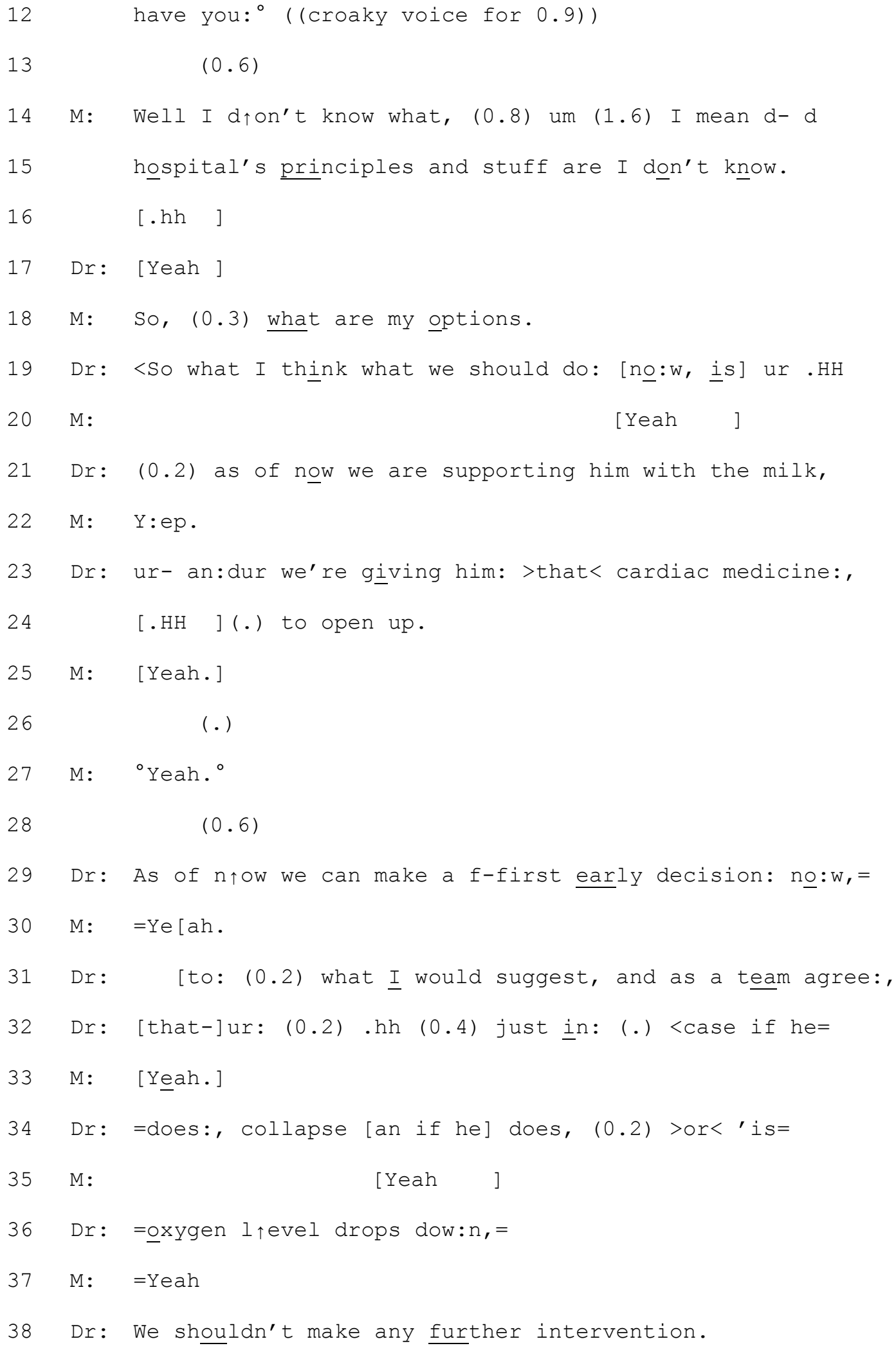

The sequence is initiated with Mum's question "So what next." This makes relevant a futureoriented conversation about Nathanial's treatment. The initial part of the doctor's response 
looks superficially collaborative, using the pronoun "we" at lines 3 and 5. However, the decision-making itself does not turn out to be collaborative; rather the doctor will recommend, unilaterally, the course of action.

We have identified two key features of recommendations, exemplified in the above extract. First, the doctor prefaces his recommendation about Nathanial's treatment decision with the phrase "the right thing for this baby" (lines 5-7). This phrase was used recurrently throughout decision-making sequences, and often as a preface to strong recommendations from doctors. It is almost idiomatic, and places constraints on the parents: if they disagree with the course of action, they are not acting in the best interests of their baby. Second, the recommendation is further couched as being the shared perspective of the team of doctors (line 31). Challenging the recommendation of a team of experts is a difficult thing to accomplish interactionally; doctors are more entitled to the medical knowledge upon which decisions are made than parents are (Heritage, 2012). The recommendation itself: "what I would suggest.....we shouldn't make any further intervention" (lines 31-38) uses a verb of moral obligation ("shouldn't") which strongly favours the recommended course of action. No other course of action is considered. Furthermore, "I would" is a modal construction which frames the "suggestion" as patterned or predictable and therefore a course of action that is normative (Edwards 2006), and more difficult to resist. These design features set up acceptance as the 'preferred' response, and means that challenging or resisting such a recommendation is interactionally more difficult to achieve for the parent.

Note also, however, that before the actual recommendation happens, the doctor invites Mum to share her thoughts (lines 11-12), resembling what Maynard (1992) calls a 'perspective display sequence'. By seeking the mother's perspective, the doctor forecasts the upcoming bad news, enabling his subsequent bad news to be fitted to her perspective. Mum does not provide her perspective on 'what next', however, but goes on to ask what her 
options are - providing instead, her preference to get information prior to providing her perspective (line 18). But instead of listing options next, the doctor begins to deliver a recommendation "what we should do now". The "we" is ambiguous; it might refer to him and Mum, as a collaborating unit, but it might refer to the medical team. So, although Mum specifies a preference for options, a recommendation is prioritised nevertheless; the bad news turn is not fitted to Mum's perspective. The extract ends with the doctor's clear recommendation (line 38). We return to the conversation a few moments later.

\section{Extract 2: F1R3, Part B (60-91)}

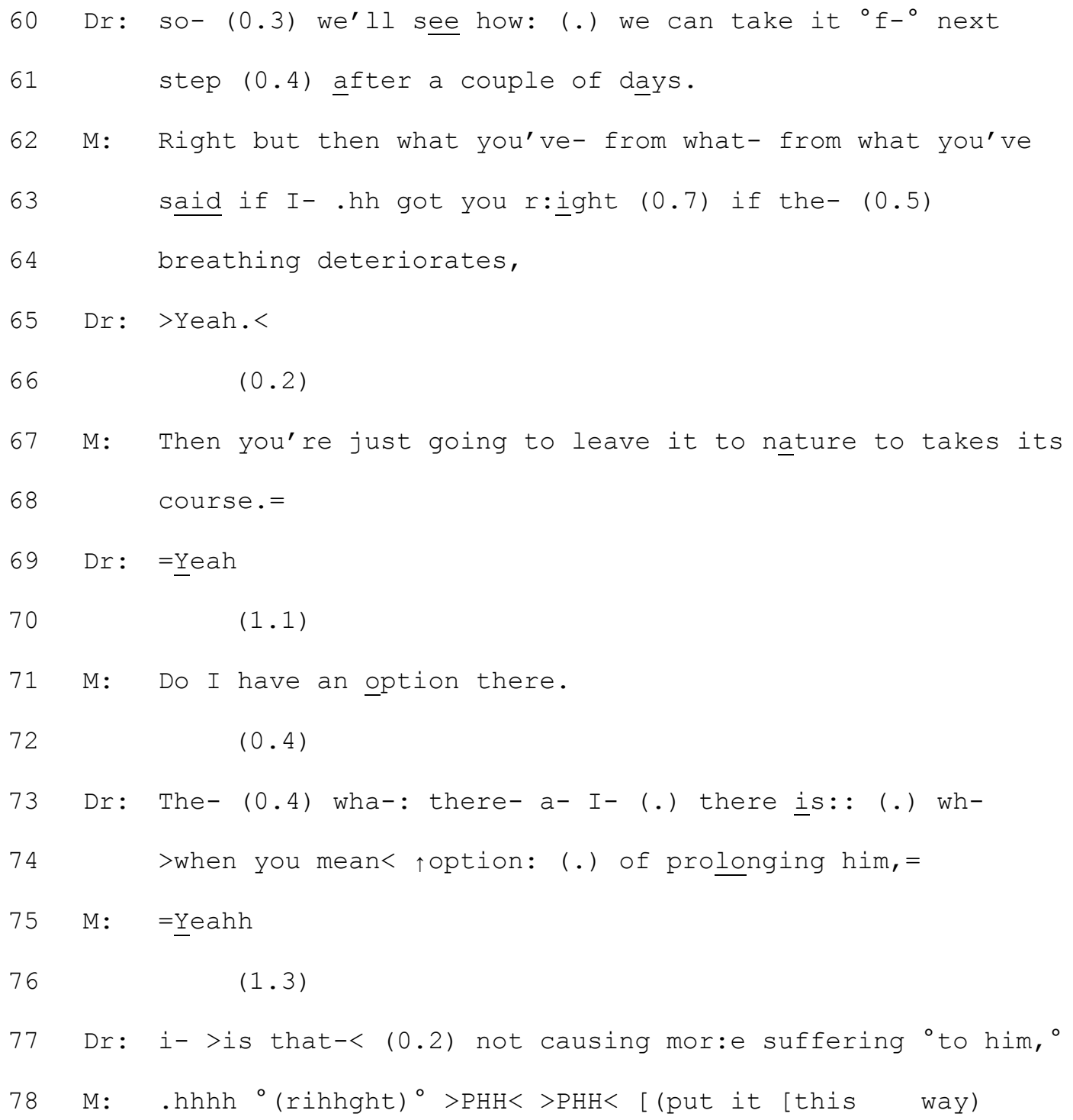




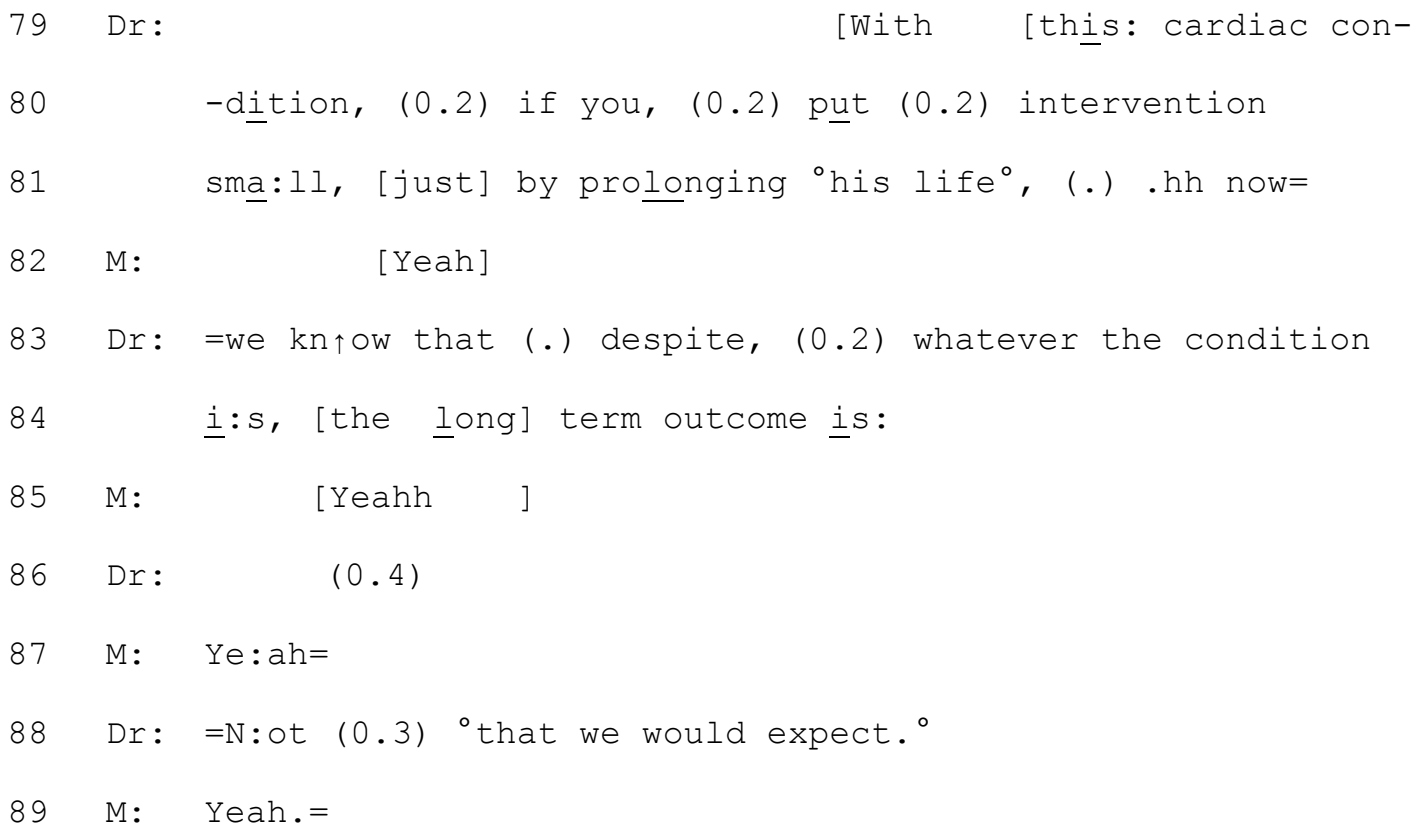

In the interim between Extracts 1 and 2, Mum did not accept the course of action or display alignment with the recommendation, responding with only unmarked acknowledgments (e.g., "aright" and "mm") which, according to Heritage and Sefi (1992) show implicit resistance. She shows further resistance (lines 62-68) by formulating the negative upshot of what is being proposed ("Right but..."). At line 71, Mum orients explicitly to the limited optionality presented by the doctor, by challenging its absence ("Do I have an option there.").

So, having asked for options earlier, Mum now recognizes that she has not been presented with any. The doctor continues to limit optionality through questions that package the alternative option negatively (lines 77-81). His turns are littered with markers of trouble and perturbations (cut-offs and restarts), making the beginning of a dispreferred response; one that foreshadows bad news (see Maynard, 2003) and one that does not affiliate or align with Mum's turn. That is, the doctor fails to align by not responding to Mum's yes-no question (line 73) with a 'yes' or a 'no', and by not actually providing any requested options. Instead, he asks a negatively framed question, " $>$ is that- $<(0.2)$ not causing mor:e suffering 'to him, ${ }^{\circ}$ " which is highly challenging in return, seeking agreement with an assertion as 
opposed to eliciting an answer to a question (see Bolinger, 1957, Heritage, 2002). The doctor effectively proposes that Mum's preferred course of action would result in the suffering of her own baby, at her behest.

A similar pattern can be observed in Extract 3, from a different consultation, which starts at the end of the doctor's unilateral recommendation.

\section{Extract 3: F1R4}

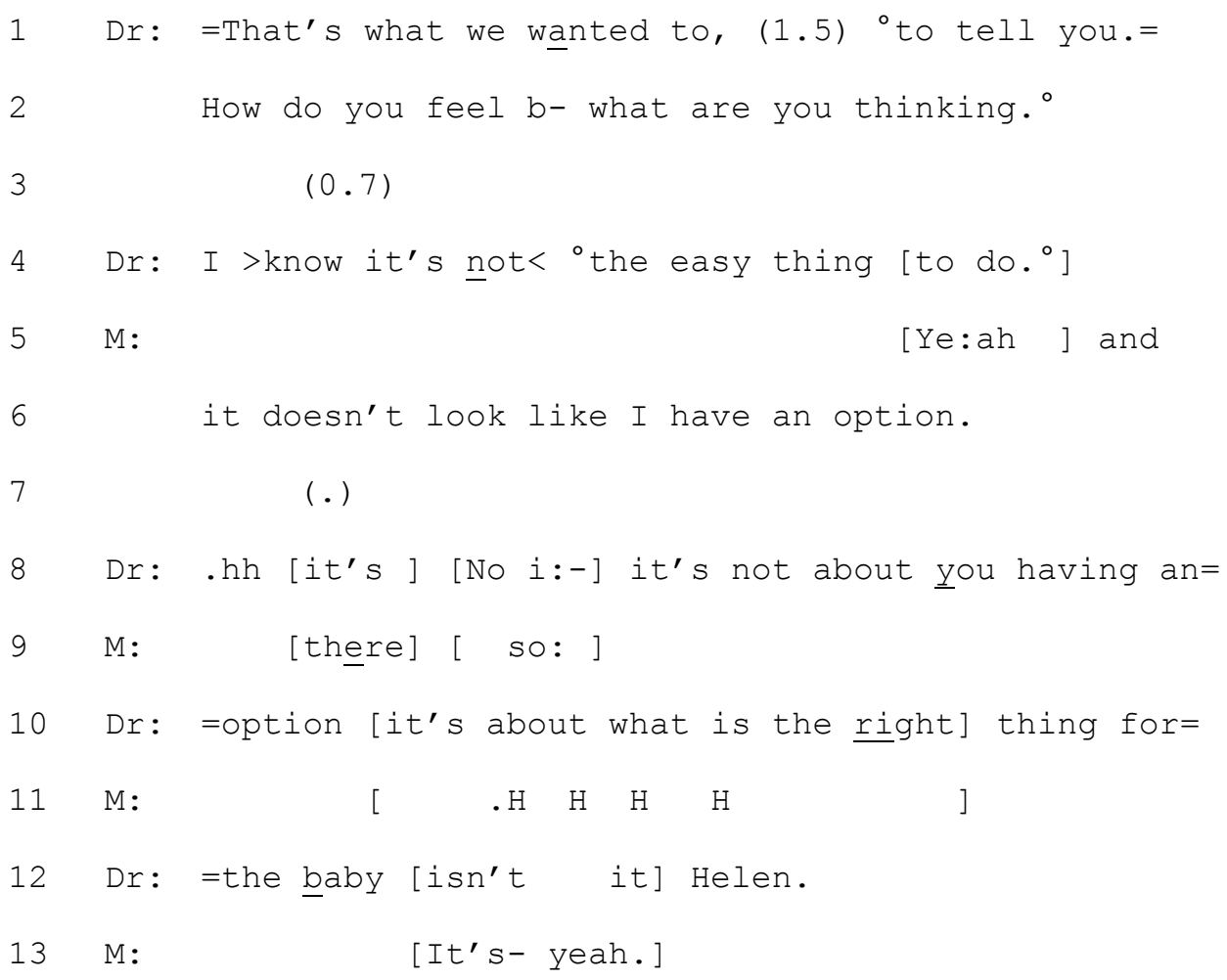

Like Extract 1 ("what are your thoughts"), the doctor invites Mum to comment on the decision-making process as it is unfolding ("what are you thinking"). This time, although the question seeks the recipients' perspective, it does not work to forecast bad news delivery and does not align this with Mum's perspective because it comes after a one-sided recommendation: “... what we wanted to tell you” (line 1). After no ratification from Mum (line 3), the doctor orients to the difficulty of the decision, but does not present alternative 
options. Like Extract 2 (“Do I have an option here”), Mum's response makes explicit the constraint that is being imposed by orienting to the apparent lack of options that she has: "it doesn't look like I have an option" (lines 5-6). This explicit orientation goes further than the previous extract, by actually stating that this appears to be the case, rather than enquiring about it. Indeed, in this case Mum is being informed about a decision that has essentially been made. The doctor's account for presenting only one option is to invoke a contrast between 'options' and "the right thing for the baby." The tag question (“isn't it Helen") pursues acceptance of the latter and from a position of certainty with regards to the answer (see Hepburn and Potter, 2011; Heritage and Raymond, 2012).

In the next conversation, from a different case, the doctor has been telling Mum about her baby's poor condition before reporting on how he had presented the case at the 'grand round' (a weekly meeting for doctors and nurses to discuss the management of serious cases). We join the conversation as the doctor presents the decision of the team.

\section{Extract 4: F24R2, Part A (1-49)}

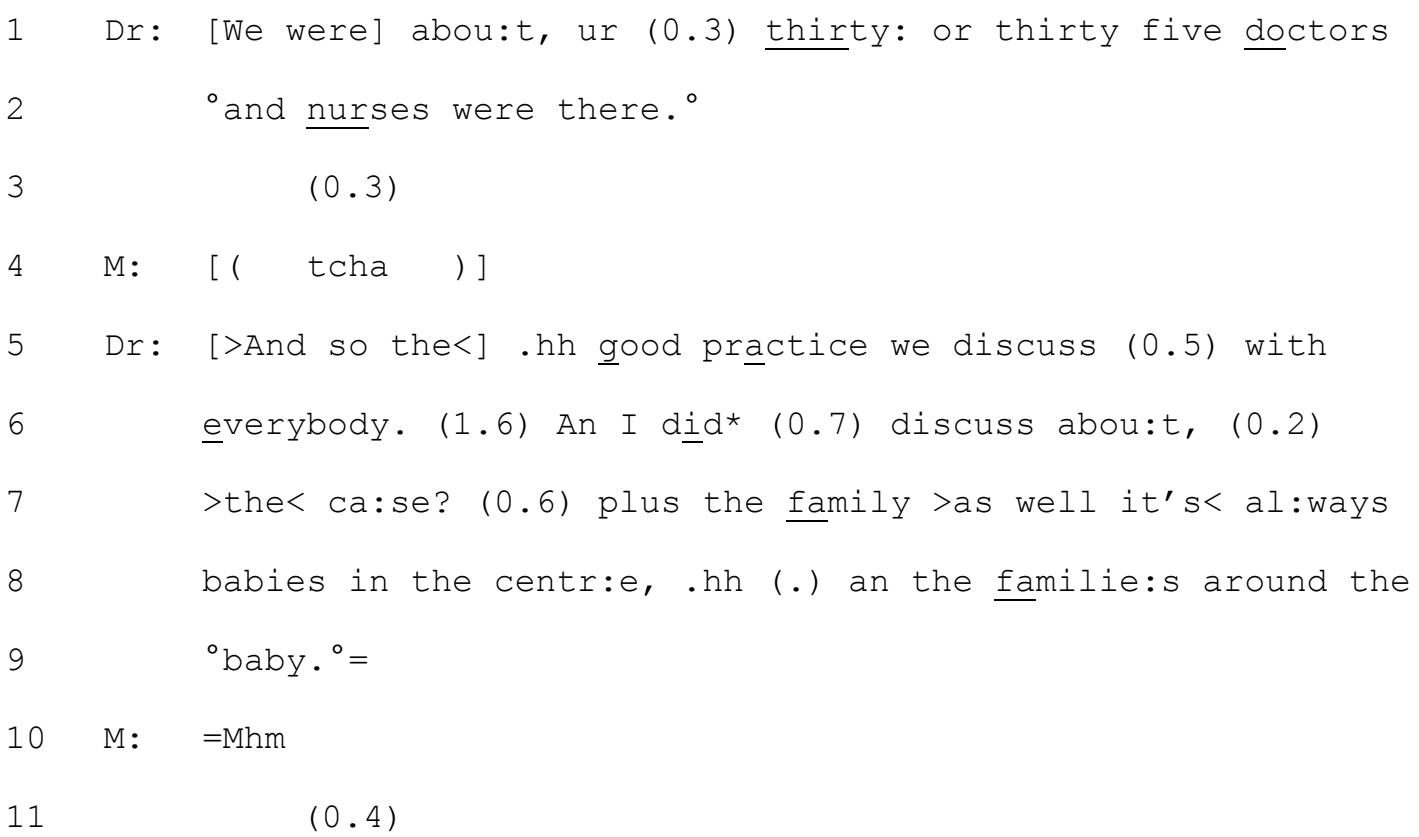




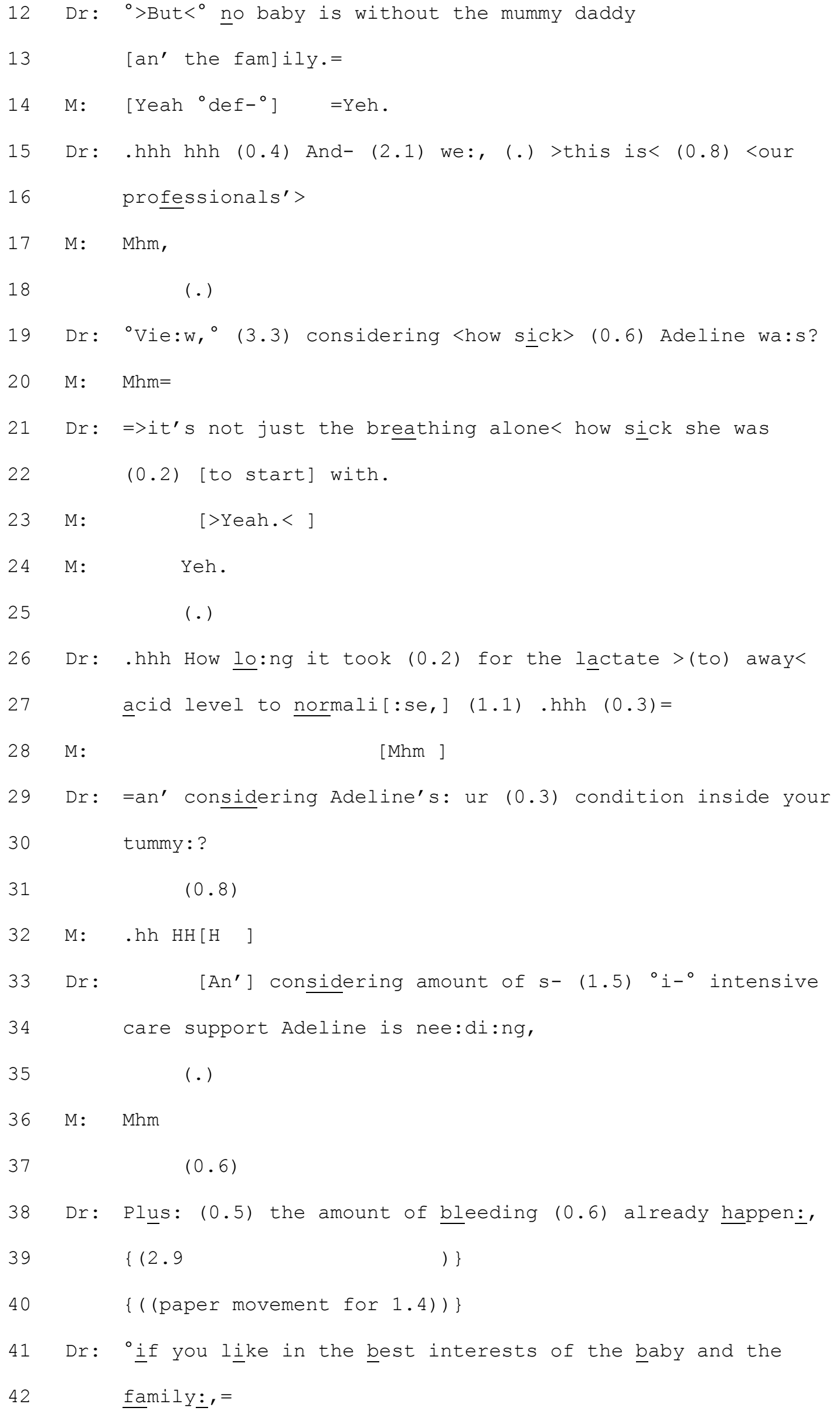




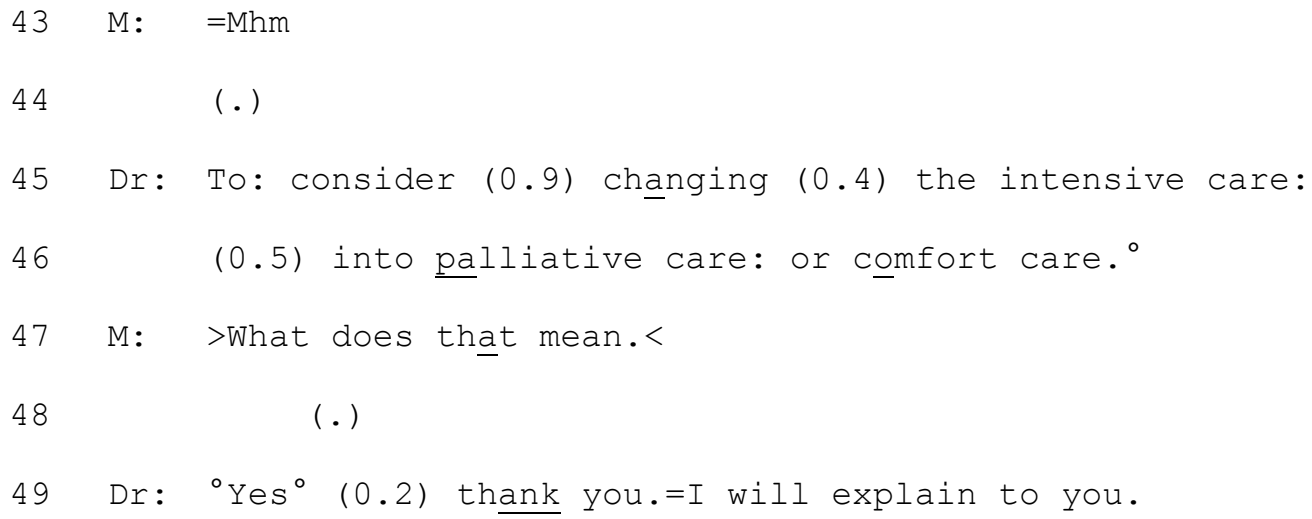

Like previous extracts, we can see how a one-option decision, to move from intensive care to palliative care (lines 45-46) is presented as that of an expert team (lines 1-6;15-16) and in the baby's 'best interest' (line 41, but also implicitly at line 8). Note the extent of this joint decision is emphasised through the enumeration of 35 doctors and nurses. This builds the recommendation that follows as corroborated (by professionals), and therefore robust, making disagreement or resistance a challenging thing to do (see Potter, 1996). The doctor builds a case for this future course of action by presenting a number of pieces of evidence (lines 1938) prior to the delivery of the recommendation itself. These design features - particularly the enumeration of professionals in agreement and adverse aspects of the baby's condition - build a strong preference for acceptance of a particular future course of action. They also work to forecast the bad news recommendation that follows (Maynard, 2003).

Rather than accept or reject the decision, Mum asks a question of the doctor, to explain his recommendation (line 47). This question is somewhat challenging; Mum may not understand the doctor's recommendation but her response is couched in a direct way that holds the doctor accountable for not having presented something comprehensible to a nonexpert. A similar response to one-option recommendations was also observed in the following extract from another consultation. 


\section{Extract 5 F8R1, Part A (1-5)}

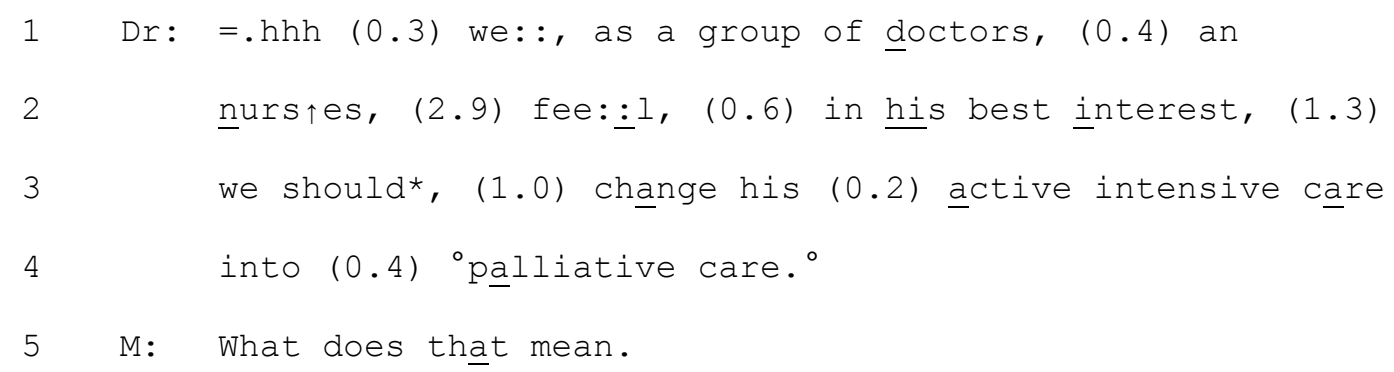

In Extracts 4 and 5, note the use of 'palliative care' which shrouds the bad news, as what is essentially being proposed is that the baby will be allowed to die (see Maynard, 2003).

We return to the conversation in Extract 4 following the doctor's explanation of palliative care, throughout which Mum produces only unmarked acknowledgments.

\section{Extract 6 F24R2, Part B (110-137)}

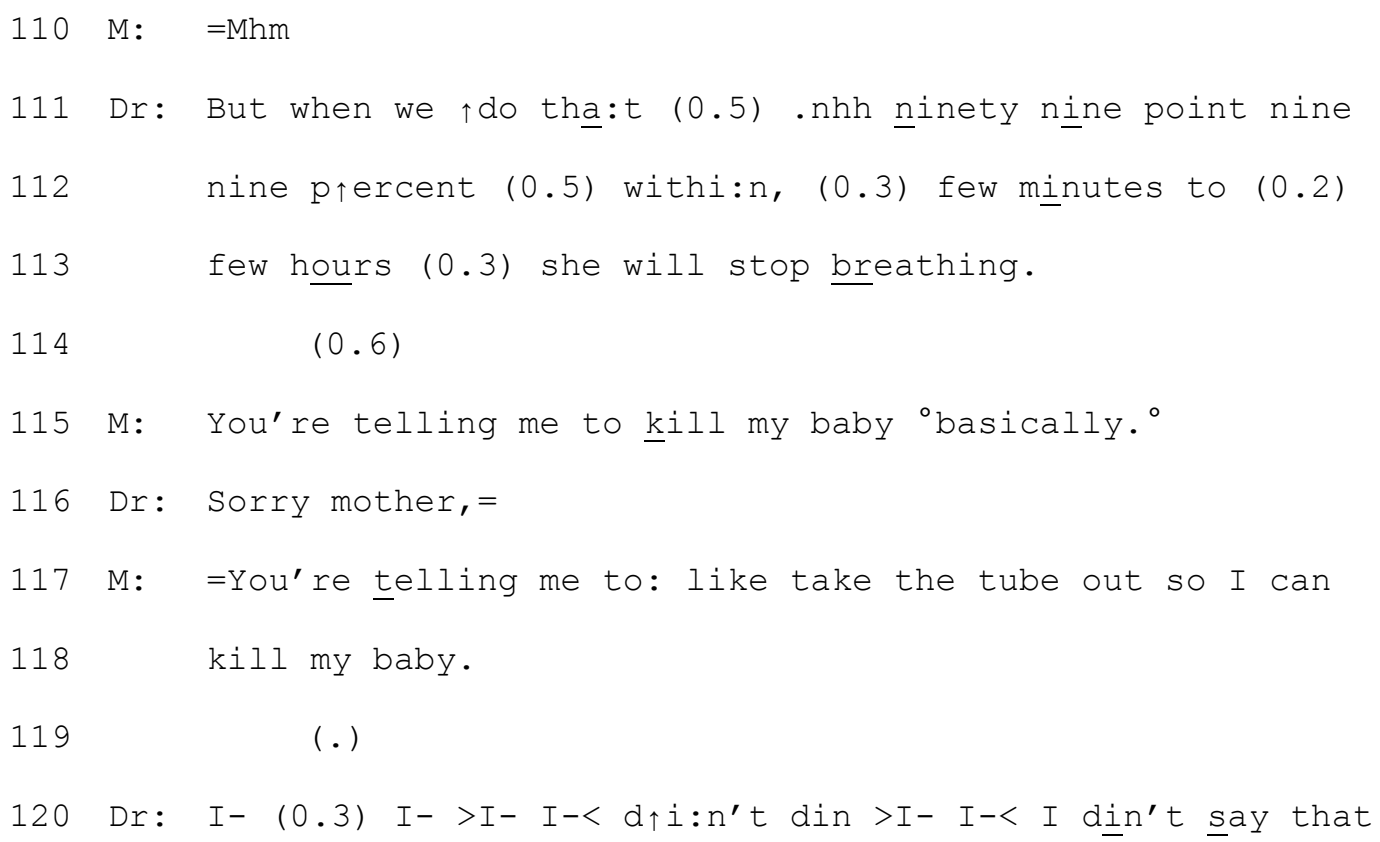




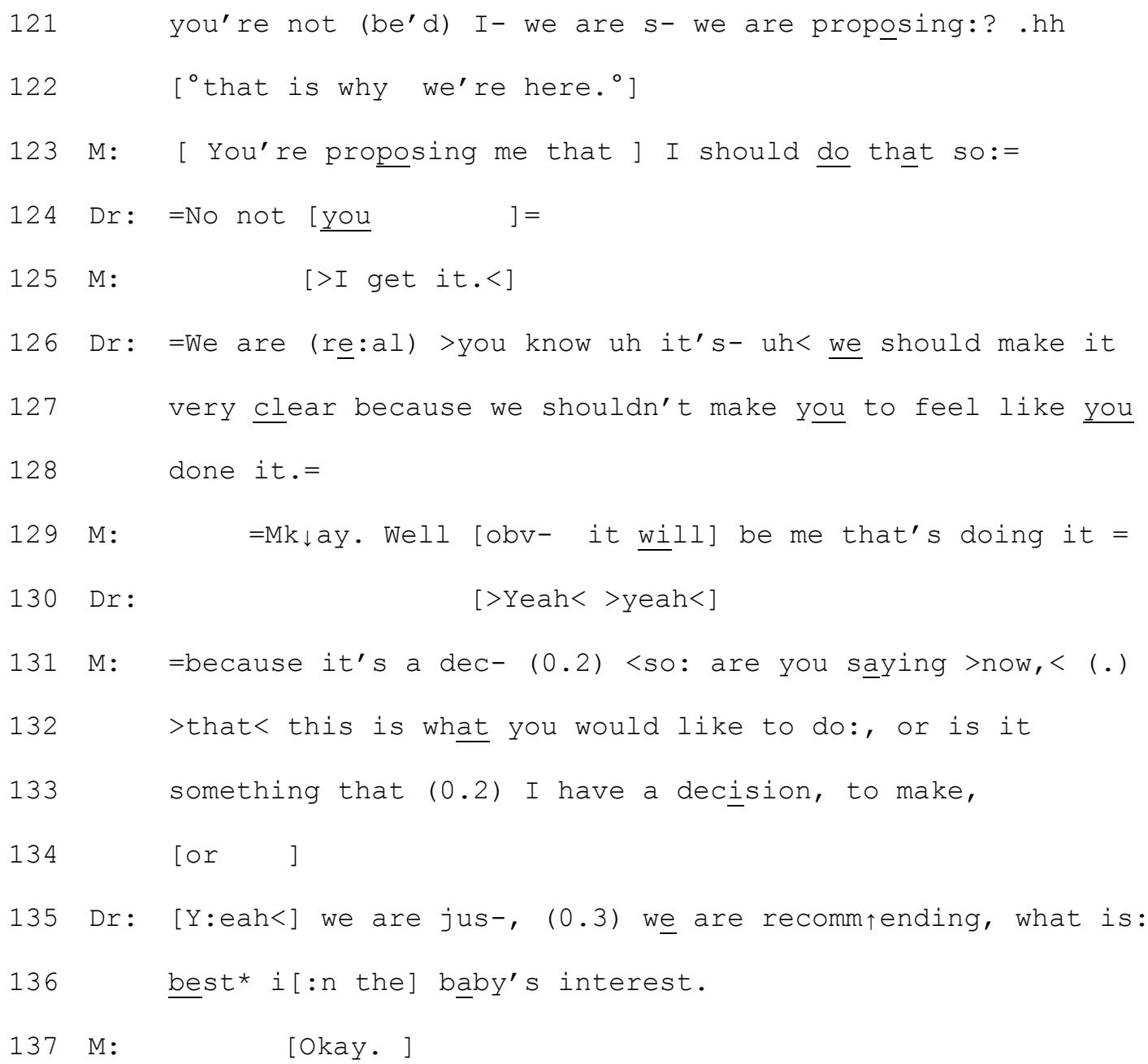

This sequence is particularly problematic for parent-doctor alignment. The doctor first explains the outcome of moving to palliative care (lines 111-113). In response, Mum formulates what she takes as the negative upshot of this decision: "You're telling me to kill my baby basically." (line 115). Leaving the patient - in this case the parent - to formulate a bad news diagnosis has been identified by Maynard (2006) as a dispreferred or interactionally problematic thing to do, and we see evidence of this here. By enquiring into the nature of the action, Mum resists the constraint imposed by it. Like the parents in previous extracts, Mum raises the issue of her lack of choice ("you're telling me to"). Her formulation is particularly challenging in that she is using an upgraded, extreme case formulation of what the doctor has said: 'kill' as opposed to the baby 'stopping breathing.' This has similarities with examples of 
formulations identified by Drew (2003): one in a radio call-in and another in a news interview, where in both settings, formulations were designed to be particularly tendentious in order to create controversy. In response to Mum's formulation (with "kill” being in sharp contrast to the more euphemistic ways that doctors typically refer to end-of-life and/or death), the doctor issues an open class repair initiator ("Sorry mother"), which can be a marker of interactional trouble and through which the doctor provides a slot for Mum to reframe her action (Drew, 1997).

However, Mum continues to resist the doctor by repeating her challenging formulation (line 117-118). She inserts new information "take the tube out" but does not reformulate either the agency of the activities under discussion ("you're telling me") nor the marked use of "kill my baby" (lines 116-118). By continuing with her challenge, the doctor is wrongfooted, or put in an interactionally difficult position: note the perturbations throughout line 120: “I- (0.3) I- >I- I-<d $\uparrow$ i:n’t din >I- I-<”. He also works to reframe the decision in a more positive light; as something the doctors are responsible for rather than Mum having to carry that burden. Furthermore he minimizes the action by saying that "we are jus- recommending" (lines 135-136), adding that the recommendation is "in the baby's best interest". Towards the end of the extract, Mum inquires further into the degree of choice that she has ("this is what you would like to do:, or is it something that (0.2) I have a decision, to make").

In Extract 6, then, we see further evidence for an emerging pattern, in which doctors' recommendations are shored up via recourse to the 'best interest' idiom, but met with resistance from parents and shot through with interactional trouble about the constraints such a course of action foster. Extract 7 is a final example of parent responses to doctor-initiated presentations of a one-option recommendation. 


\section{Extract 7: F8R1, Part B (28-37)}

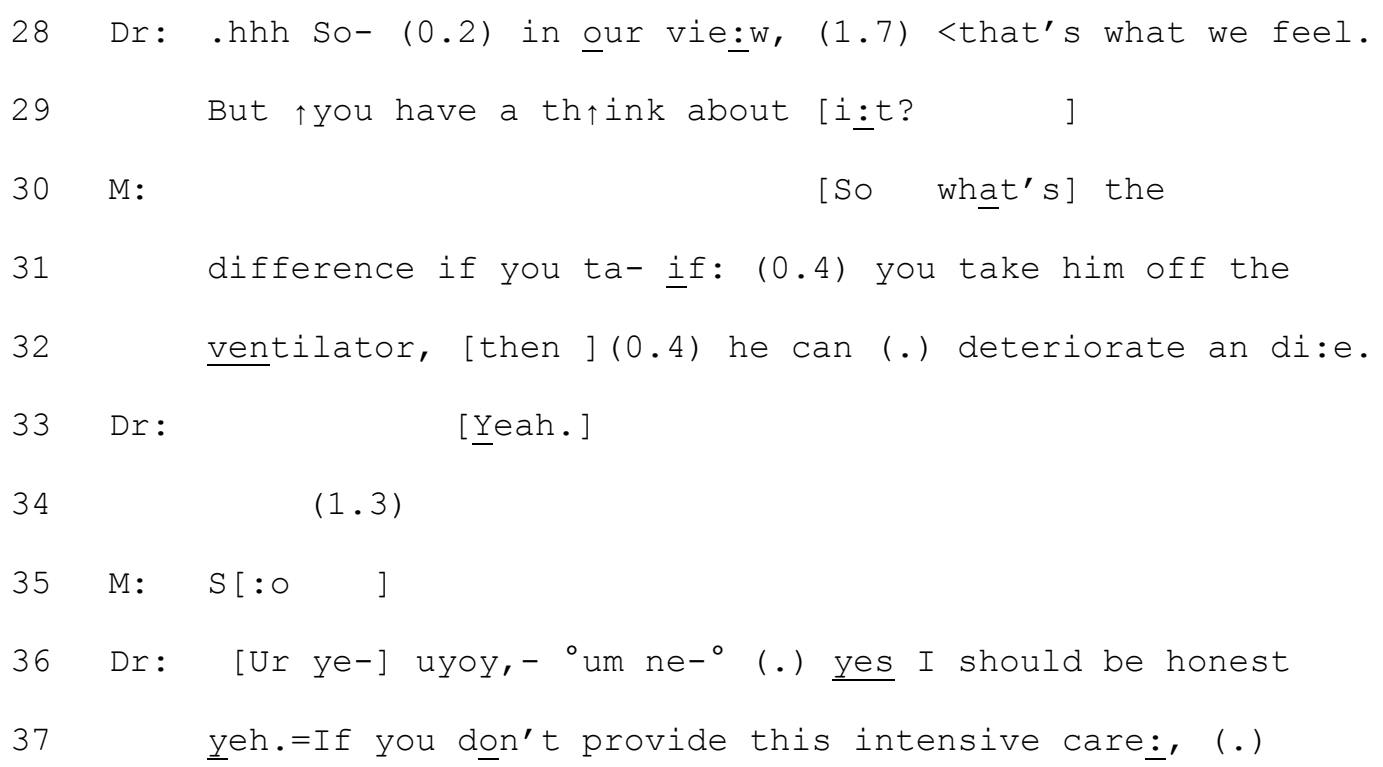

Again, the doctor presents the medical view and invites comment from Mum (see Extracts 1 and 3). Like the mother in Extract 6, Mum's response is to negatively formulate the upshot of the doctor's recommendation using the marked term "die", which is followed by interactional trouble (a delay, line 34, and perturbations in the doctor's response, line 36).

In this section, we have seen that misalignment and disaffiliation between doctors and parents follows a particular practice for initiating decision-making: making recommendations. In each case, the parent resists a unilateral course of action by asking explicitly about their options, asks challenging questions, or formulates challenging turns about the upshot of explanations. In other words, it seems that trouble and communicative conflict of some kind follows unilateral decision-making. We now move on to contrast this finding with what happens when an alternative approach to decision-making is taken. 


\section{Providing options}

The second analytic section shows how decision-making can be organized differently, via presenting options, and how this organization provides for quite different consequences. The examples resemble a type of 'option-listing' identified by Toerien et al. (2013) in neurology encounters, and we show not just how options are formulated but how optionality opens up interactional space for parents to assert their preference and in a way that recommendations do not.

In Extract 8, the doctor has just informed the parents of the MRI report for their baby who has had severe lack of oxygen at birth ('severe HIE'). A prediction of moderate to severe disability has been made. The baby's breathing is currently being supported by a ventilator but is reaching a stage where he will naturally be taken off to allow him to breath nonassisted. The difficult decision here concerns whether the baby should be put back on the ventilator if he starts to struggle, given his poor prognosis. This is the first time the decision has been raised, but there have been some discussions around the possible redirection of care from intensive to palliative previously.

\section{Extract 8: F4R1, Part A (1-128)}

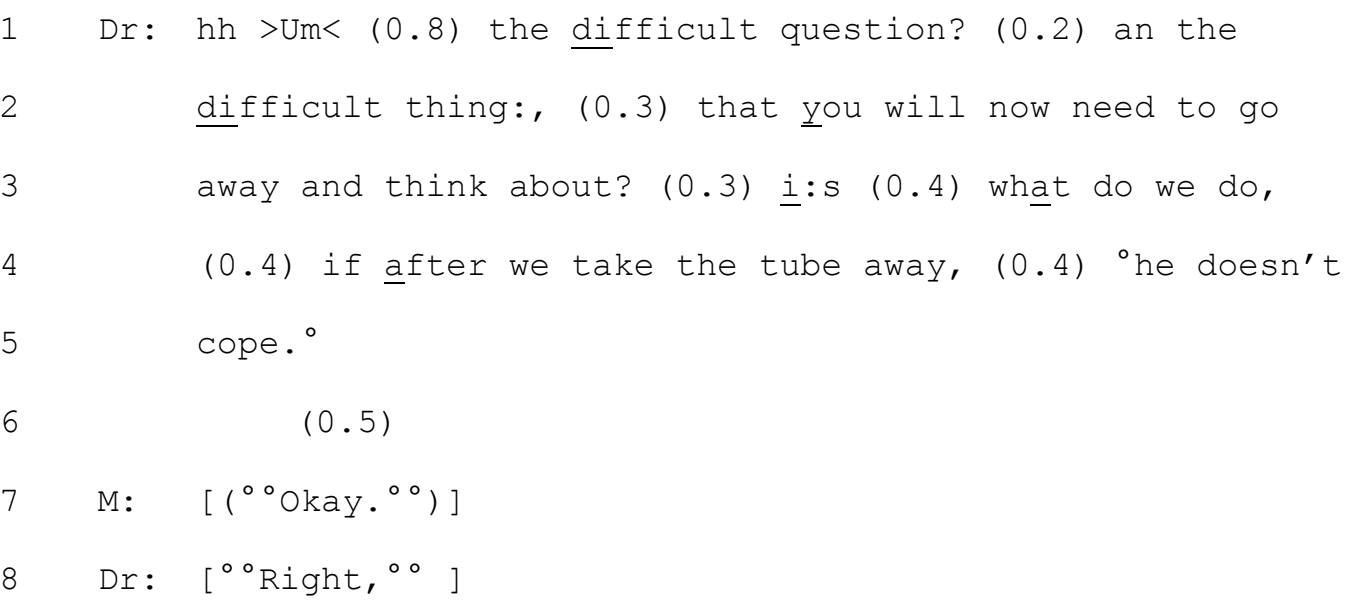


Note that, unlike the sequences presented in the first section, issues of 'best interest/doing the right thing' are not mentioned in the doctor's preface about a "difficult question" that the parents need to "go away and think about" (lines 1-3). The design of his turn presupposes the parents' involvement in the decision without specifying what the doctor's perspective or preference is. The decision is, in this case, also deferred and there is no interactional requirement for an immediate answer (lines 2-3).

The conversation continues, following the doctor's emphasis on the difficult nature of the decision and the value in having a clear plan in place.

\section{Extract 9: F4R1, Part B (157-185)}

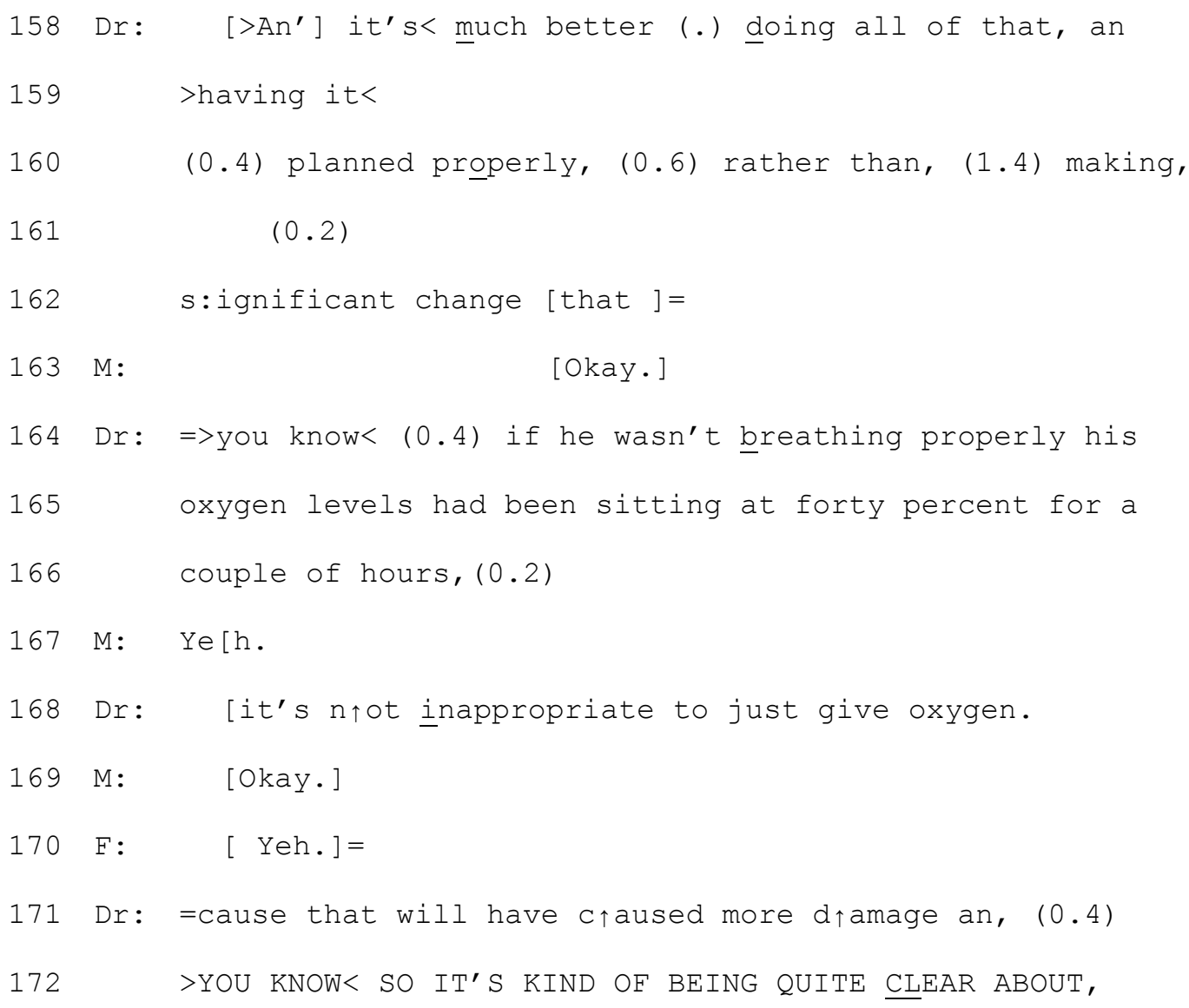




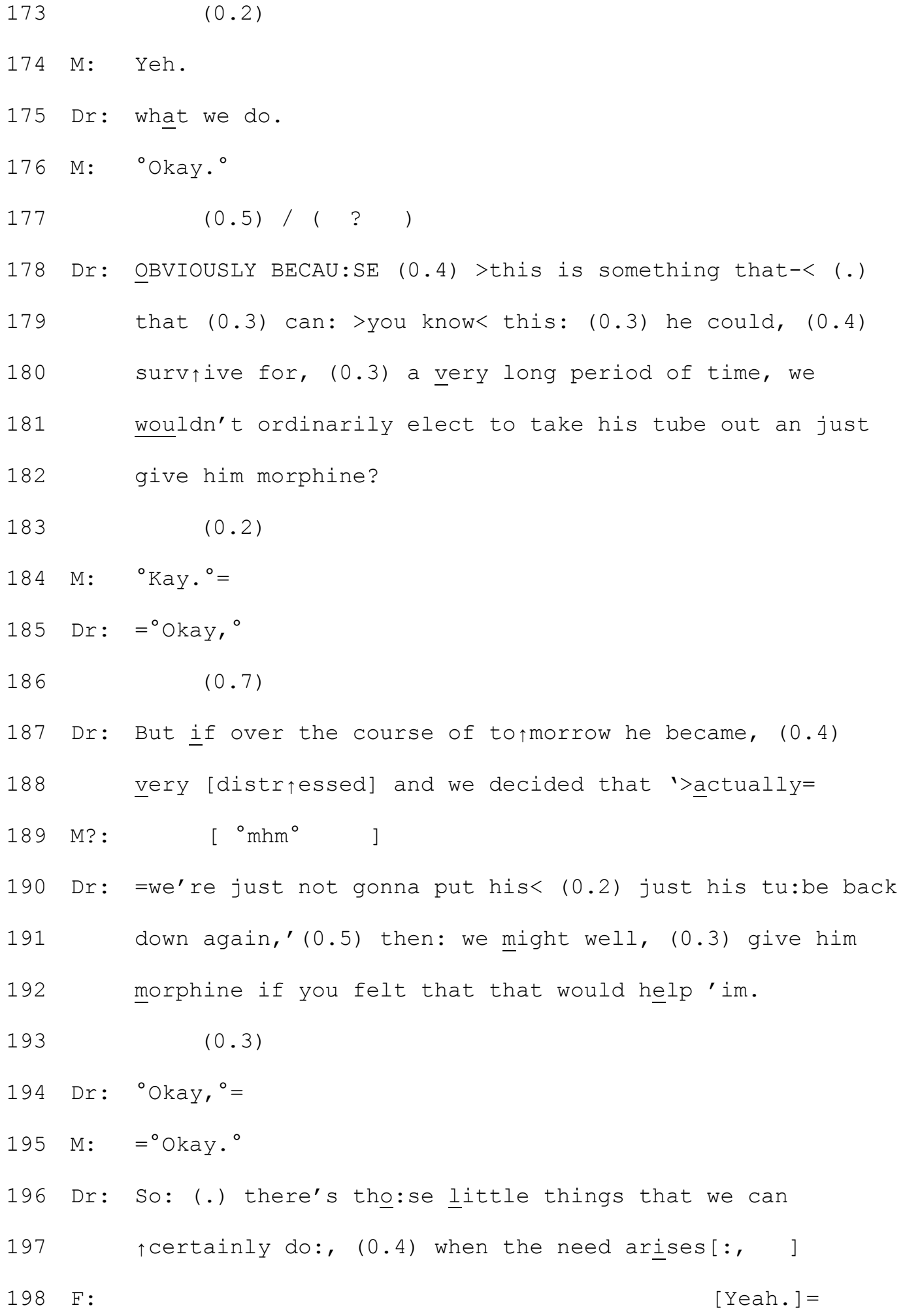

The doctor presents the parents with information regarding support for the baby and the options that might be considered, using conditional 'if-then' formats. Should the baby struggle to breath, he could be provided with oxygen (line 168), or oxygen and morphine 
(lines 178-192). Packaged within these options is also the possibility of putting the ventilator support back in place: "it's not inappropriate to just give oxygen" (line 168), indicating that it could be appropriate to do more. Interestingly, the doctor actually lists the options that are other than reinserting the tube, thus favouring the provision of oxygen and morphine through the delivery of information, rather than in the form of a recommendation. Still, this is the less invasive of approaches in which life sustaining treatment could potentially be withheld and therefore the baby allowed to die.

The implications for the trajectory of the decision-making process are two-fold. First, by deferring the relevance of the decision to the next day, the doctor makes relevant acknowledgment tokens in response to the information being provided as opposed to an accept/reject response to a recommendation (see Silverman, 1997). Second, by presenting options, an acceptance or rejection of a unilateral recommendation is not made relevant and the parents are invited to present their preference in the future.

The segment below, from the same conversation, follows the doctor's summary of the uncertainty regarding when the need will arise for breathing support following extubation.

\section{Extract 10: F4R1, Part C (250-270)}

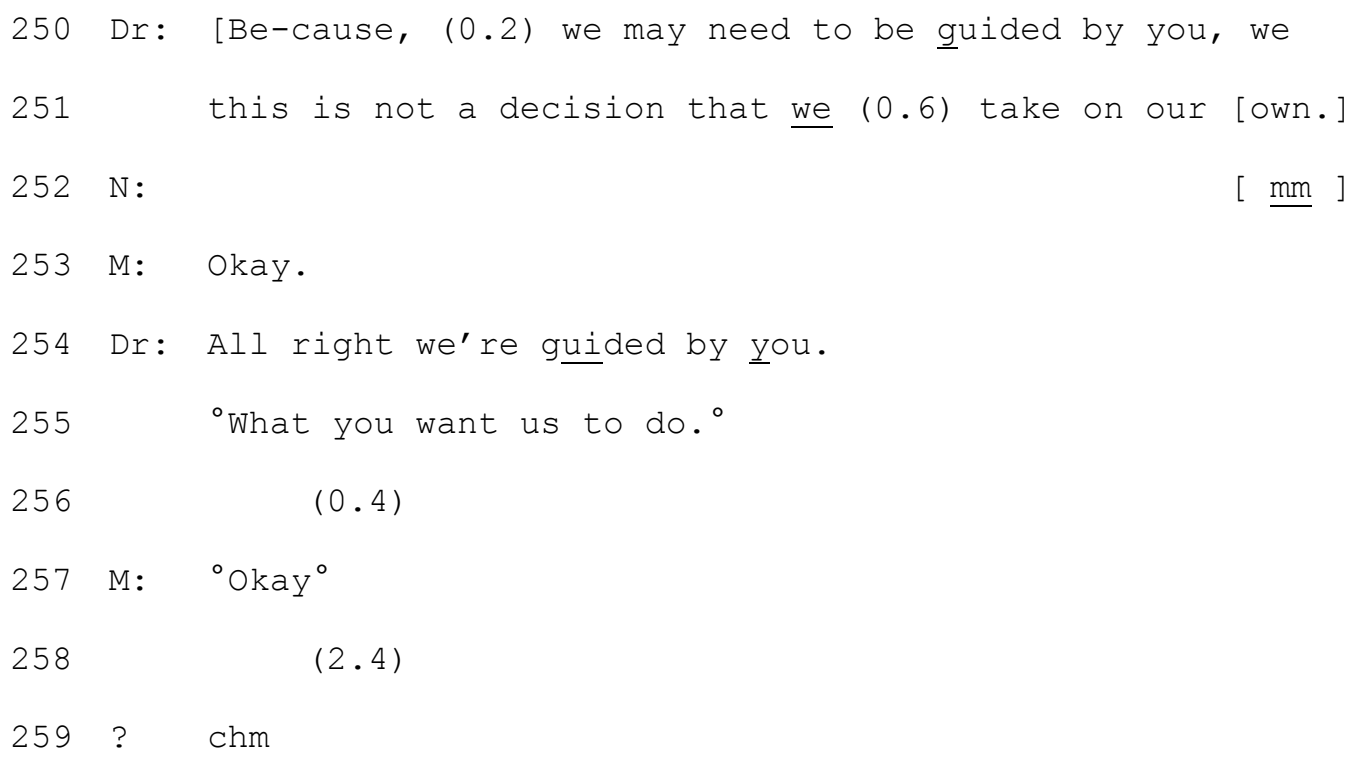




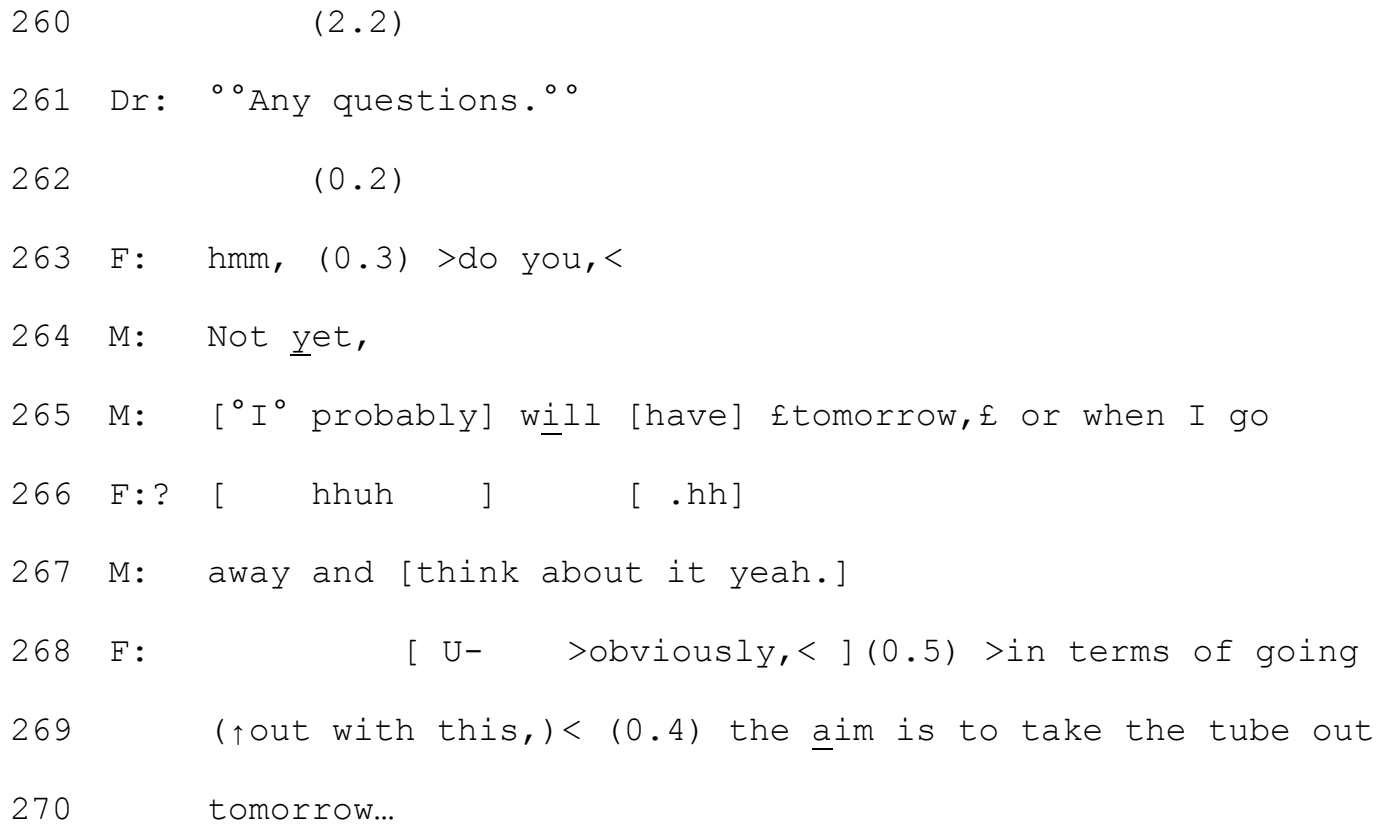

The doctor closes the sequences by framing the decision as not final and one that is guided by the parents. In doing so, the doctor avoids favouring a particular decision and therefore removes immediate interactional constraints to make one. A third implication for this format for decision-making is that the parents are able to deliver inquiries in an interactional space where they are not framed as challenges. In Extract 10, the doctor invites the parents to ask questions (line 261) and the father then begins to ask about what it is they need to decide following extubation (line 268).

Compare the father's question in Extract 10 above with the extract below, taken from the same conversation as Extracts 5 and 7 in the first analytic section, where Mum is asking questions following a unilateral 'recommendation'.

\section{Extract 11: F8R1, Part D (59-67)}

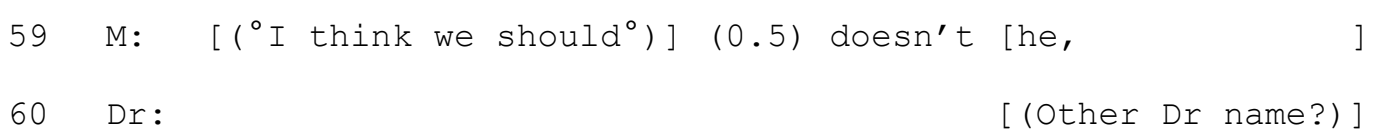




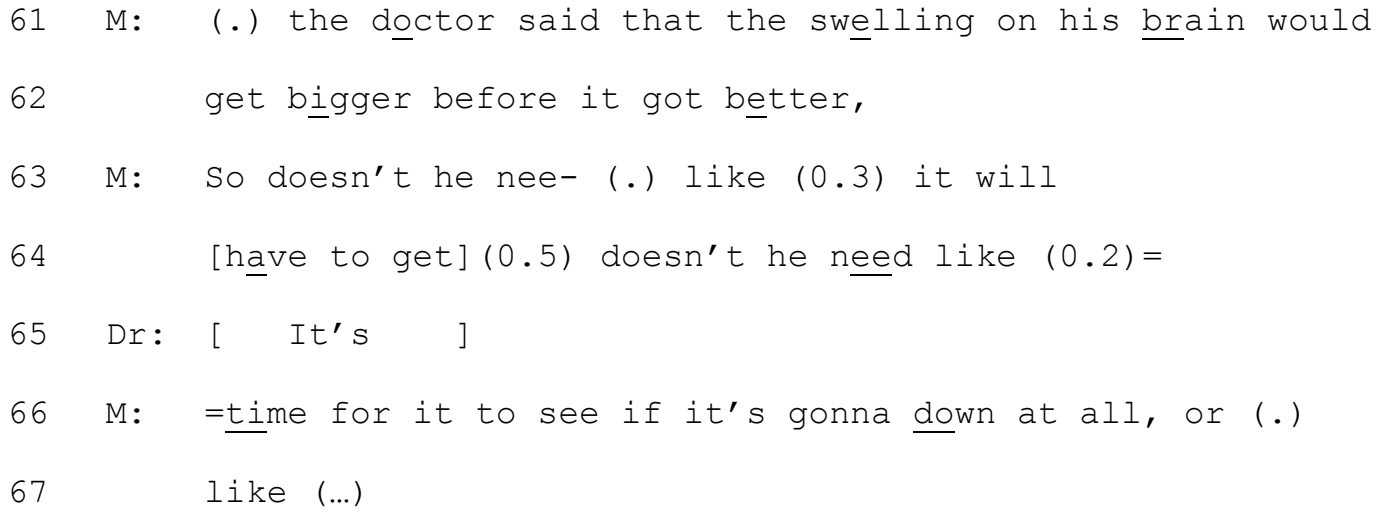

At line 63, Mum uses a negative interrogative question design (line 63) which challenges the doctor's recommendation explicitly (Heritage, 2002); that is, “doesn't he" resists the position being proposed in the discussion thus far. Mum is in an oppositional position to the doctor, in which her inquiries push back against the constraint that has been imposed by his recommendation.

Extract 12 comes from a conversation with the same family as in Extracts 810 , and occurred 20 days after the conversation in those extracts. It comes after options have been provided by the doctor regarding withholding care and provides a further example of how an interactional space for questions is opened up following the articulation of options rather than recommendations.

\section{Extract 12: F4R3 (171-182)}

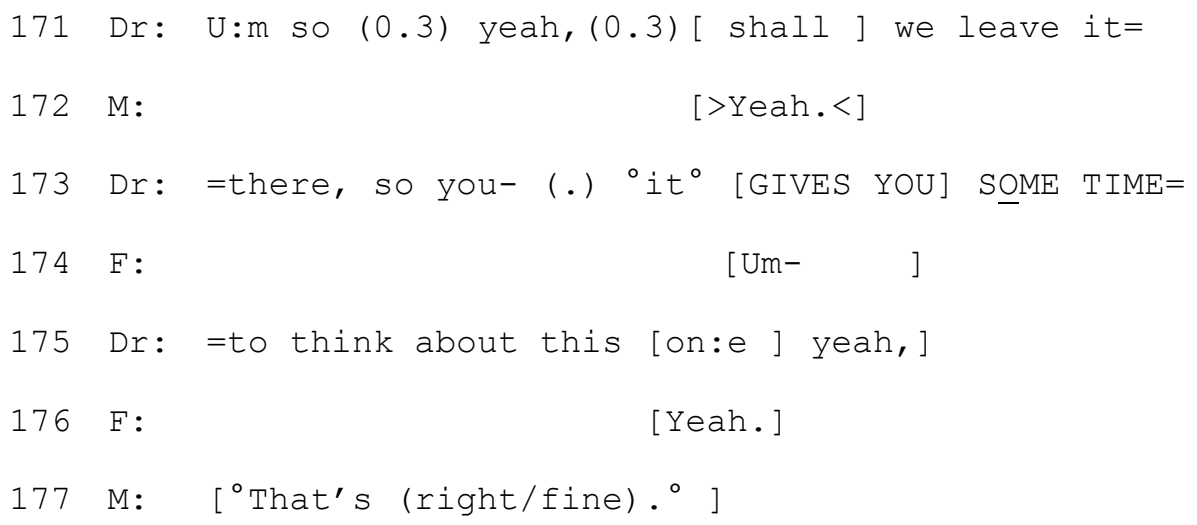




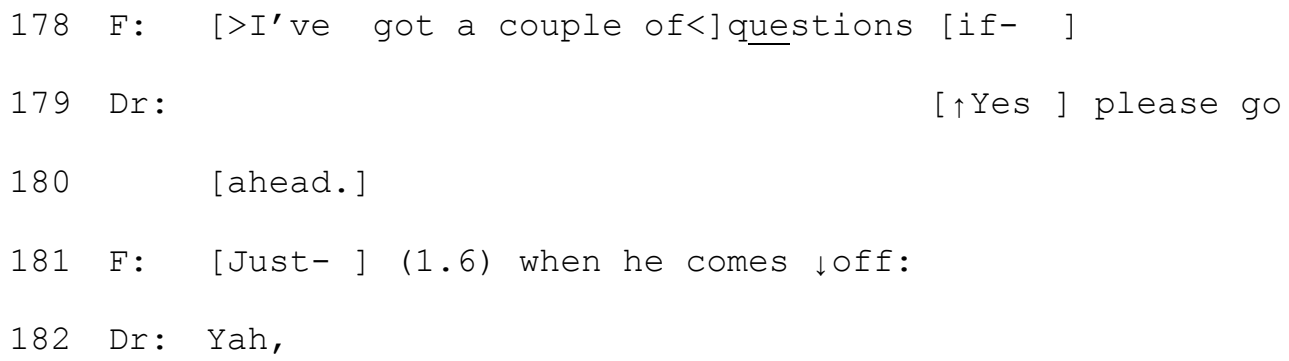

As in Extract 10, Dad initiates a question-answer sequence with a pre-sequence about "a couple of questions" (line 178), which is then given the go-ahead by the doctor. The questions have been invited rather than taking the form of a challenge to what has been proposed (as in Extract 11, following a recommendation).

In the next example, the consultant has come to talk to the parents who have a threatened delivery of twins at 23 weeks gestation. One of the twins has no amniotic sac and the subsequent discussion focuses on the other baby, who has better chance of survival. The consultant is talking to Dad as Mum is receiving oxygen and is unable to speak. The consultant has informed Dad that, at this stage, the babies have a very slim chance of survival and a significant risk or severe and significant disability. The option of palliative care has already been raised at this point as something that some parents (with the doctors agreeing) would think is best for the baby, and a description of palliative care provided.

\section{Extract 13: F16R1}

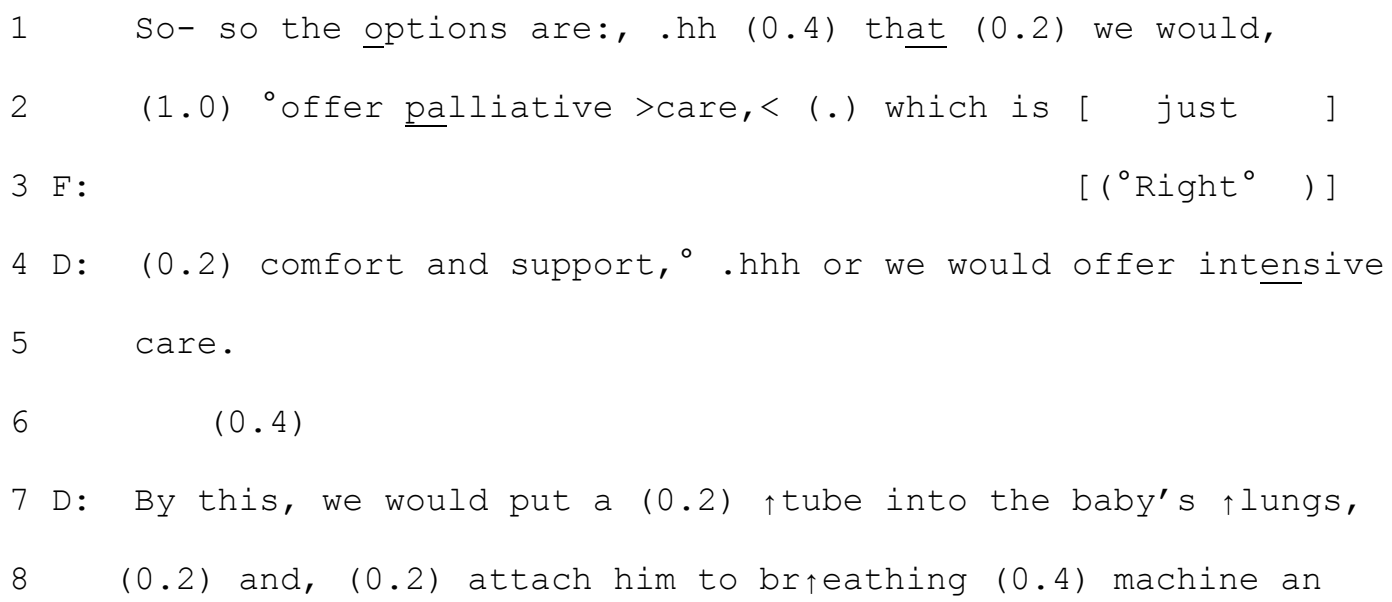



the whole delivery, .hhh and labour, and then we would admit

11 him to the neonatal unit. .hhh $(2.3)$

13 D: And see how he goe:s from there: but he may not (0.2) make 14 it.=Even if we, do all of that, he may not make it through

15 the labour? (0.2) .hh (.) he may not (0.3) make it (0.9)

16 once [he has] (0.2)

$17 \mathrm{~F}: \quad[$.HHtH ] Because urm=

18 D: =born.

$19 \quad($.

$20 \mathrm{~F}$ : the issue of: : that palliative care, (0.3) .hhh (0.2)

21 odon't ${ }^{\circ} \mathrm{mm}:$ : (0.7) ou- o- >of the- $\uparrow$ of the, of the, $<$ I un- I

22 understand the reasons for it, (0.4) but (2.0) tch (0.6) I

$23 \uparrow$ don't she will be able to >cope.<

( (Dad continues to expand on how Mum will find it hard to resign herself to the fact that the babies will not make it))

65 F: So:. (1.2) ${ }^{\circ}{\text { it' } \mathrm{s}^{\circ}}^{\circ}(0.2)$ really gonna be, bit of a: (1.5)

66 >it's gonna be really hard for her emo- emo[tionally.<]

67 D: $\quad[<$ So $]$ what

68 you're saying $>$ is that you feel that mum would like to give

69 the babies every (0.2) chance.=Is that? (0.5) right?

70

$(0.3)$

$71 \mathrm{~F}$ : I guess so yeah.=

72 D: $={ }^{\circ}$ Yeah. ${ }^{\circ}$

$73 \quad(0.4)$

74 D: [But mum is ] too sleepy [to[(0.3) [talk] at the moment.=An

$75 \mathrm{~F}:[\mathrm{I}$ per- \#go:\# $] \quad[\mathrm{mm}[\mathrm{:}[:[]$

76 D: anyway I think we have some time [to have these] (0.2)

$77 \mathrm{~F}:$

$\mathrm{mm}: \quad]$ 
D: discussions.

((Dad continues to expand on how Mum will find it hard to

resign herself to the fact that the babies will not make

it) )

102 F: Obviously on- on the other ha- on the other hand, .HHH

103 ((chair moves/(0.6) )) (5.5) i- (1.5) it might sound a bit

104 crude but (1.7) eh I wouldn't want to start:, (0.2) have the

105 urm: (0.8) tch ${ }^{\circ}$ but $^{\circ}(0.4)$ a- added burden of: (0.6) having

106 to look after a- (0.2) ch- child, .hhh (0.4) who's gonna

107 who's gonna- (0.8) .hhh (0.3) not having, (0.2) who's gonna

108 hav:e, $(0.2)^{\circ}$ is disad- (m) whose who is kind of: (0.5)

109 disadvantaged. $=$

The consultant presents two options: an 'either/or' decision between palliative care and intensive care (lines 1-5). The options are both offered and parental choice is emphasised. Palliative care was described earlier, perhaps explaining why more attention is given to intensive care in this extract. However, intensive care is framed negatively as something contingent: "if he survives the whole delivery" (lines 9-10) and with limited prospects "he may not make it" (lines 13-16). Furthermore, 'he may not make it' is emphasised by repetition to mark two different time points: in labour and once he has been born.

Dad takes several extended turns, weighing up the two options. He acknowledges palliative care as something appropriate: "I understand the reasons for it" (lines 21-22), and goes on to assert what he takes to be Mum's perspective "I don't (think) she will be able to cope" (lines 23-24). There is some trouble in delivering his response, which might be explained in part by English not being his first language. He elaborates his perspective in the omitted section (lines 24 to 64), stating how Mum will find it hard to resign herself to the fact that the baby will not survive; the upshot is formulated in lines 65-66. The doctor also 
formulates the upshot of Dad's turn in terms of its relevance to decision-making: "you feel that mum would like to give the babies every chance", and seeks confirmation of this from Dad with the tag question. Dad provides a hedged confirmation with 'I guess' (line 71) and after a delay, the actual decision is then deferred by the consultant, to a time when mum is able to talk. ${ }^{1}$

Dad therefore able to articulate his own preference and his concerns about having a disadvantaged child (lines 102-109). While he orients to the potentially problematic hearing of this preference ("it might sound a bit crude"), and his turn is littered with delays and perturbations, he nevertheless communicates his perspective. In particular, he assesses the two options in a non-adversarial context; the perspectives are not positioned as challenges to a recommendation. This supports Toerien et al.'s (2013) findings that option listing, as seen here, provides interactional space for parents' preferences to be stated; going beyond a less agentive and more minimal accept/reject response and thus implicitly carving out an environment for shared decision-making

In the final extract, the baby has severe neonatal encephalopathy and is one month old. The consultant has met with the parents and community nurses for the baby's discharge planning meeting. It is relevant that the baby has poor secretion management and is not currently able to bottle feed. The doctor recaps the conversation thus far before moving on to raise the issue of whether and how far the baby will be actively resuscitated should the need arise, once the baby has been discharged home.

\footnotetext{
${ }^{1}$ This opportunity actually arises in the current conversation and after exploring the two options extensively, the parents state their preference that they would like the twin with the better chance to have intensive care and the other twin to receive palliative care. However, the decision is still ultimately contingent on how long the babies can stay in the womb and an assessment on the baby's condition at birth.
} 


\section{Extract 14: F15R1}

1 Dr: So:, (0.5) to recap, we talked abou:t (1.1) rooming in,

11 Dr: because you had this discussion: in: in- with the other we talked about the vaccination. $>$.hh $<$ Now one (0.7) one more impo:rtant and (0.3) s:ensitive issue I wanted to talk i:s, (0.4) tcha (2.9) if: (0.9) ${ }^{\circ}$ for ${ }^{\circ}$ our bad luck if (0.2) things >you know< abruptly: stopping breathing: or stops heart-.hhh/(0.8) we need to make a plan and we need to write in the notes [like, ]=

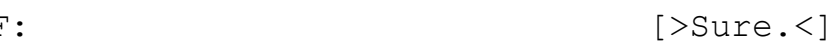




$$
(0.2)
$$

35 Dr: [Would-

36 F: [Yeah.

39 M: Unchanged.

40 F: Unchanged as to our last decision,

41 M: Yeah.

42 F: Which was a: :<an escalation from the previous decision.

$46 \mathrm{~F}: \mathrm{U}: \mathrm{m}:(0.8)$ \#ur\# the- the current (0.5) the current thinking is that*<if: Aran <requires> (0.4) intub $\uparrow a t i o n$ again,

49 Dr: $\quad[>m m<$

50 F: [ that) (0.2) we are fine to do that,

51 Dr: ${ }^{\circ}$ Okay $\cdot{ }^{\circ}=$

$52 \mathrm{~F}:=$ And $(0.6)$ then make a decision as to > whether< that's 53 continued, <once he's (.) intubated.

54 Dr: ${ }^{\circ}$ Okay $\cdot^{\circ}($ (mouthed) $)$

$55 \quad(0.6)$

56 F: Ur:m: (0.4) but we would not want (0.2) ur if- if his

57 heart, (0.3) ur: gave up, we would not want that (0.3)

$58 \quad$ [ resusc]itated.

59 Dr: $\left[\mathrm{O}^{\circ} \mathrm{kay} \cdot{ }^{\circ}\right]$

60 Dr: $\underline{o}^{\circ} \mathrm{kay} \cdot{ }^{\circ} \cdot \mathrm{hh}$ 
Again, the decision is presented as a collaborative activity ("we need to make a plan", line 6); rather than a team recommendation, and the parents are included. The doctor lists possibilities for treatment (lines 22-26), should the need arise, which starts with the least amount of intensive care and ends with the most. The parents are also asked whether they would like to be given a recommendation or to express their preference directly, as they have had these discussions before (lines 28-33). This option is delivered following a 2.3 second silence from Dad. This nicely demonstrates the doctor's responsiveness to the possibility that the Dad may not wish to make this decision. 'Best interest' is only mentioned here in terms of offering the parents the possibility of a recommendation from the doctors' perspective (lines 31-32), rather than in the initiation of the decision point itself. This suggests that the baby's best interest is already known and yet 'from the professional point of view' raises the possibility of alternative, parental point of views. The parents respond by presenting their preference in an extended way, rather than taking up the option of a recommendation. There is some hesitation from Dad at first, but this may be about making sure he is aligned with Mum. Dad does not seem to present his preference as something dispreferred or problematic and the absence of an account provides evidence for this.

We have shown that, when doctors use an option-listing format in decision-making sequences, the trajectory of the interaction is much smoother, with aligned participation, than when recommendations about a particular course of action are made. Our analysis supports Toerien et al.'s (2013) findings that option-listing provides space for the recipients' preference to be stated, going beyond a less agentive and more minimal accept-reject response. 


\section{DISCUSSION}

This paper presents an analysis of decision-making conversations between medical consultants and parents of critically ill newborn babies. Decisions about life-sustaining treatment, or withdrawing that support, represent some of the most delicate and difficult conversations a parent may have to participate in for their child. We have therefore sought to understand what conversational practices may be identified that provide for aligned decisionmaking between doctor and parents. We identified two main conversational organizations for decision-making, with clearly different trajectories - which we have termed 'recommendations' and 'options'.

In recommendation sequences, doctors made reference to a robust, corroborated team decision, and one which should be made in the best interest of the baby. These recommendations were designed to strongly favour a particular course of action. Anspach (1993) reported similar findings when observing end-of-life decision-making, whereby doctors recurrently used recommendations and couched as a 'united front'. Anspach argued that doing so "obscures controversy in favour of consensus and narrows the options presented to the parents" (p. 93). Our analysis revealed such recommendations constrained parents, who sometimes articulated explicitly this constraint by reference to their "limited options". This strategy also frequently led to parents asking challenging questions and resulted in misalignment between parties. In contrast, Anspach (1993) observed that parents did not tend to resist such strong recommendations and would often withdraw from the neonatal unit instead. This difference is perhaps a reflection of a more recent assertion of patient autonomy, as opposed to the more traditional paternalism in doctor patient relationships.

Such resistance in response to recommendations has been found elsewhere in decisionmaking sequences. For instance, Quirk et al. (2012) found that psychiatric patients displayed 
resistance when decisions were pressured, but asked questions following more open decisionmaking designs. Ekberg and LaCouter (2014) similarly found that when decision-making was achieved through suggestions rather than questions, patient resistance followed next. In the case of advice-giving, where the recommendation concerned the recipient's future actions in particular, Heritage and Sefi (1992) showed that health visitors' advice to first time mothers was more readily accepted when a stepwise approach was taken, fitting the advice to the perspective of the parent. Indeed, explicit forms of advice, compared with advice given through questions or assessments, have been shown to put more constraint on recipients' subsequent actions. That is, recipients are not given space to specify possible contingencies because an accept/reject response is expected next (Shaw, Potter, Hepburn, 2015). The strong forms of resistance shown in our analysis, and following strong recommendations in these other settings, demonstrate this particularly constrained position in which alternative perspectives or contingencies are not provided for.

We found elsewhere in our data that, when parents aligned with recommendations, it was in terms of passive acceptance rather than via a more agentive statement of preference. This is in contrast to active resistance, similar to that identified by Stivers (2005), in which parents ask questions which challenge the recommendation. In short, there is little evidence that recommendations involve collaboration, 'patient-centeredness', or shared decisions. Parallels can be drawn with the unilateral recommendations identified by Toerien et al., (2013), and Collins et al., (2005) in their research settings of decision-making in neurology and oncology interactions, respectively.

When doctors used recommendations, we found that there was little discussion throughout about the mechanics of the proposed course of action. This left parents to request this information or simply accept the management of death as a given. Making recommendations, therefore, seems to embody the expert or paternalistic model of the doctor- 
patient relationship (cf. Orfali 2004). In using recommendations, doctors essentially closed down the discussion, to the extent that parents' alternative perspectives were framed as challenges

In contrast, we found that when doctors presented options, a different interactional trajectory opened up, characterized by strong alignment between parties. Key features of these sequences included an orientation to joint decision-making, the construction of the action as a 'plan' rather than a decision, the provision of information that did not explicitly favour a particular outcome, the listing of options rather than recommending a single course of action and deferring the relevance of a decision from the immediate interaction. We also found that, either through invitation from the doctor, or via a pre-sequence from parents, the option format provided opportunity for parents to ask questions. These questions were formatted in a collaborative, rather than challenging way. This is possible because the questions come before a decision has been made; any question following a strong recommendation is necessarily resistant. In option-giving sequences, parents were able to assert their preference without misaligning with the doctor, as well as not simply acquiescing to professional judgement.

In essence, in option-listing sequences, questions and preferences arise in a nonadversarial context whereby decision-making is not contaminated by controversy between the speakers; what Whalen, Zimmerman and Whalen, (1988) refer to as 'activity contamination'. Whalen et al showed how, in an American emergency call, an impasse was reached because the caller and call-taker were not interactionally aligned. Rather than a question-answer sequence, each speaker's turn became framed as a challenge and dispute became prioritised as the main activity. In our data, recommendation sequences became marked by challenges and interactional trouble; the activity of decision-making became contaminated by the adversarial context through which it arose. 
There are certain clinical scenarios where invoking the baby's 'best interests' as a strategy may be appropriate, such as in cases where death appears to be inevitable for the baby and a managed end of life strategy is preferable to prolonging life. However, even here, there are always choices as to how death can be managed, that can be described and discussed. In the recommendation cases, there seemed to be a commonality that the chance of survival was (at least presented as) poor, suggesting that this design might be fitted to a situation where limiting life support is more clearly in the best interest of the baby. However, when options were put forward, this also included cases when the chance of survival was equally poor. Whether the chance of survival is highly unlikely or not, however, by presenting options rather than recommendations, parents are afforded the possibility of exploring treatment possibilities so that they ultimately arrive at an informed and collaborative decision. By exploring options, the parents are afforded the interactional space to have their perspectives aligned with the doctor's. However, when doctors use recommendations, parents' perspectives are not solicited and their options are closed down. Exploration of alternative options is positioned as a challenge to what the doctor has proposed. Beyond the mechanics of the interaction, the lack of options also leaves the parent with anxieties about the commitment of the clinical team to their child if they were to take an alternate path 'against advice'. Some doctors consider this expert model and the primacy of their opinion to be preferable (XXXX). Doctors are instructed to use recommendations (GMC advice) and a test of 'best' interests (Nuffield Council of Bioethics, 2006), without a clear framework as to how these are to be arrived at (Wilkinson, 2013). Transparency in how such conclusions are derived needs to be part of the conversation with parents if their autonomy is to be respected. 'Best interest' is a difficult notion for parents and must be carefully explored by them within the context of their unique family circumstances, alongside the clinical notion of best interest and associated uncertainties. By exploring alternative 
options, parents have the opportunity to satisfy their short and long term needs of coming to terms with the decision and this could be important in the long term outcome for parents. Parents have to live with the decision they make, so giving them the interactional space to explore options is crucial.

Our analysis has shown that presenting options does not necessarily equate to parents taking the burden of decision-making. Doctors are still able to manage this moral responsibility by making options available in two ways: 1) parents are positioned as collaborative decision makers and not sole decision makers, and 2) parents can subsequently be presented with the option of a stronger recommendation should they indicate a reluctance to state their preference (as shown in the final extract, although this is the only example in our data). As such, this approach has the potential to be individualised and responsive to the recipient. Key here is offering the parent choice to begin with as once a recommendation has been put on the table, a constrained 'accept/reject' response is made a conditionally relevant next action and therefore becomes a challenge to be retracted. As Anspach (1993: 125) has argued “...a well-intended but paternalistic attempt to protect parents from guilt may, ironically, produce the very effect it is designed to minimize and may deter, rather than facilitate, vigilant information processing."

It is also important to note that, while presenting options can invite parents to be more fully involved in decision-making, this does not preclude the possibility of certain options being more persuasively presented, as we saw in Extracts 9 and 13. Indeed, Quirk et al. (2012) show how decisions can be directed through the discounting of certain options that are listed. As Anspach (1993) has argued, the two paradigms of minimal and more active parent involvement in neonatal decision-making should be regarded as poles on a continuum. Exploring how options might be presented subtly (or otherwise), in ways which steer the decision, may be an interesting area for future research. 
Our findings support Duffy and Reynolds's (2011) observation that doctors are clearly aware of national recommendations for shared decision-making but are not necessarily sure about how to put this into practice. While references to 'best interest' by doctors when giving recommendations are understandable, given its emphasis in national guidelines (e.g., $\mathrm{RCPCH}, 2004)$, to conflate its philosophical use into the language used to initiate such decisions has the potential to elicit less opportunity for parental involvement - through which babies' best interests could otherwise be more fully explored. This occurs because of the challenging position that the parents are put in, should they wish to present an alternative perspective to a morally-weighted recommendation. The use of this recommendation strategy establishes that any alternative would 'only cause suffering', and defines 'a moral precept', which parents are likely to have difficulty disagreeing with (Anspach 1993).

Our paper has, therefore, highlighted the value of studying how decision-making actually works, as a way of developing a research basis for national communication guidance. It has provided empirical evidence of the endogenous impact of initiating a decision point through these two different designs; that is, the impact that is tractable within the interaction itself. These findings have important implications for training doctors to have more effective and collaborative conversations with parents. By becoming astute to the way turns of talk can close down decision-making sequence and, consequently, the doctor-parent alliance, doctors can begin to build a tool-kit for effective practice. With the paucity of communication skills training that doctors in this speciality receive $(\mathrm{XXXX)})$, as well as in the evidence base that informs it, we hope to, through training, enable doctors to understand how to have effective and mutually aligned conversations with the families in their care. 


\section{REFERENCES}

Anspach, R. R. (1993). Deciding Who Lives: Fateful Choices in the Intensive-Care Nursery. California, University of California Press.

Bolinger, Dwight (1957). Interrogative Structures of American English. Tuscaloosa, AL, University of Alabama Press.

Butow, P., Juraskova, I., Chang, S., Lopez, A. L., Brown, R. \& Bernhard, J. (2010). Shared decision making coding systems: how do they compare in the oncology context? Patient Educ Couns, 78: 261-268.

Caeymaex, L., Speranza, M., Vasilescu, C., Danan, C., Bourrat, M. M., Garel, M. \& Jousselme, C. (2011). Living with a crucial decision: a qualitative study of parental narratives three years after the loss of their newborn in the NICU. PLoS One, 6, e28633.

Coeckelbergh, M. and Mesman, J. (2007). With Hope and Imagination: Imaginative Moral Decision-Making in Neonatal Intensive Care Units. Ethic Theory Moral Prac (10): 3 21.

Confidential Enquirey into Maternal and Child Health (CEMACH). (2009). Perinatal Mortality 2007: United Kingdom. London: CEMACH.

Clark, S. J. \& Hudak, P. L. (2011). When surgeons advise against surgery. Research on Language and Social Interaction, 44 (4): 385-412. DOI:10.1080/08351813.2011.619313.

Collins, S., Drew, P., Watt, I. \& Entwistle, V. (2005). 'Unilateral' and 'bilateral' practitioner approaches in decision-making about treatment. Social Science \& Medicine, 61: $2611-2627$.

Costello, B. A. \& Roberts, F. (2001). Medical recommendations as joint social practice. Health Communication, 13 (3): 241-260. 
Costeloe, K. L., Hennessy, E. M., Haider, S., Stacey, F., Marlow, N. \& Draper, E. S. (2012). Short term outcomes after extreme preterm birth in England: comparison of two birth cohorts in 1995 and 2006 (the EPICure studies). BMJ, 345, e7976.

Department of Health (DOH). (2009). Toolkit for high-quality neonatal services. London: $\mathrm{DOH}$.

de Vos, M.A., Bos, A.P., Plotz, F.B., van Heerde, M., de Graaff, B.M, Tates, K., Truog, R.D., Willems, D.L. (2015). Talking with parents about end-of-life decisions for their children. Pediatric, 135 (2): e465.

Drew, P. (1997). "Open" class repair initiators in response to sequential sources of troubles in conversation. Journal of Pragmatics, 28: 69-101.

Drew, P. (2003). Comparative Analysis of Talk-in-Interaction in Different Institutional Settings: A Sketch. In P. Glenn, C. LeBaron and J. Mandelbaum, (Eds.) Studies in Language and Social Interaction: In Honor of Robert Hopper. Mahwah NJ, Erlbaum: 293-308

Drew, P. (2005). Conversation Analysis. In: K.L. Fitch \& R.E. Sanders (eds.) Handbook of Language and Social Interaction (pp. 71-102). Mahwah, NJ: Lawrence Erlbaum.

Duffy, D. \& Reynolds, P. (2011). Babies born at the threshold of viability: attitudes of paediatric consultants and trainees in South East England. Acta Pædiatrica, 100: 4246. DOI:10.1111/j.1651-2227.2010.01975.x

Edwards, D. (2006). Facts, norms and dispositions: practical uses of the modal verb would in police interrogations. Discourse Studies, 8, 475-501.

Einarsdottir, J. (2009). Emotional experts: parents' views on end-of-life decisions for preterm infants in Iceland. Med Anthropol Q, 23: 34-50. 
Ekberg, K \& Lecouteur, A. (2014). Co-Implicating and Re-Shaping Clients' Suggestions for Behavioural Change in Cognitive Behavioural Therapy Practice. Qualitative Research in Psychology, 11, 1: 60-77.

Elwyn, G., Edwards, A., Wensing, M., Hibbs, R., Wilkinson, C. \& Grol, R. (2001). Shared decision making observed in clinical practice: visual displays of communication sequence and patterns. J Eval Clin Pract, 7: 211-221.

Gillam, L. \& Sullivan, J. (2011). Ethics at the end of life: who should make decisions about treatment limitation for young children with life-threatening or life-limiting conditions? J Paediatr Child Health, 47: 594-598.

Goossensen, A., Zijlstra, P. \& Koopmanschap, M. (2007). Measuring shared decision making processes in psychiatry: skills versus patient satisfaction. Patient Educ Couns, 67: 5056.

Gwyn, R. \& Elwyn, G. (1999). When is a shared decision not (quite) a shared decision? Negotiating preferences in a general practice encounter. Soc Sci Med, 49: 437-447.

Heimer, C. A. and L. R. Staffen (1998). For the sake of the children: The social organization of responsibility in the hospital and the home. London, The University of Chicago.

Hepburn, A. \& Bolden, G. (2012). The conversation analytic approach to transcription. In: J. Sidnell \& T. Stivers (eds.). The Handbook of Conversation Analysis (pp. 57-76). Oxford: Wiley-Blackwell.

Hepburn, A. \& Potter, J. (2011). Designing the recipient: Some practices that manage advice resistance in institutional settings, Social Psychology Quarterly, 74: 216-241.

Heritage, J. (2002). The limits of questioning: negative interrogatives and hostile question content. Journal of Pragmatics, 34: 1427-1446. 
Heritage, J. (2012). Epistemics in Action: Action Formation and Territories of Knowledge, Research on Language and Social Interaction, 45 (1): 1-29. DOI: 10.1080/08351813.2012.646684.

Heritage, J. \& Maynard, D. W. (2006). Introduction: Analyzing interaction between doctors and patients in primary care encounters. In: J. Heritage and D. Maynard (eds.), Communication in Medical Care: Interactions between Primary Care Physicians and Patients (pp. 1-21). Cambridge, Cambridge University Press.

Heritage, J. \& Raymond, G. (2005). The terms of agreement: Indexing epistemic authority and subordination in assessment sequences. Social Psychology Quarterly, 68: 15-38.

Heritage, J. \& Sefi, S. (1992). Dilemmas of advice: Aspects of the delivery and reception of advice in interactions between health visitors and first time mothers. In: P. Drew \& J. Heritage (eds.). Talk at Work (pp.359-419). Cambridge: Cambridge University Press.

Jefferson, G. (2004). Glossary of transcript symbols with an introduction. In: G. Lerner (ed.) Conversation analysis: Studies from the first generation (pp. 13-32). Amsterdam: John Benjamins.

Koenig, C. J. (2011). Patient resistance as agency in treatment decisions. Soc Sci Med, 72: 1105-1114.

Koenig, C. J., Wingard, L. M., Sabee, C., Olsher, D. \& Vandergriff, I. (2014). Managing patient-centered communication across the type 2 diabetes illness trajectory: A grounded practical theory of interactional sensitivity. Journal of Applied Communication Research, 42 (3): 244-267. DOI: 10.1080/00909882.2014.911943.

Lipstein, E. A., Dodds, C. M. \& Britto, M. T. (2014). Real life clinic visits do not match the ideals of shared decision making. J Pediatr, 165: 178-183.

Makoul, G. \& Clayman, M. L. (2006). An integrative model of shared decision making in medical encounters. Patient Educ Couns, 60: 301-312. 
Maynard, D. (1992). On Clinicians Co-Implicating Recipients' Perspective in the Delivery of Diagnostic News. In P.Drew and J.Heritage, (Eds.) Talk at Work: Social Interaction in Institutional Settings. Cambridge, Cambridge University Press: 331-358.

Maynard, D. (2003). Bad News, Good News: Conversational Order in Everyday Talk and Clinical Settings. Chicago, University of Chicago Press.

Maynard, D. (2006). "Does it mean I'm going to Die?" On meaning assessment in the delivery of diagnostic news. Social Science \& Medicine, 62: 1902-16.

Mchaffie, H. E., Laing, I. A., Parker, M. \& Mcmillan, J. (2001). Deciding for imperilled newborns: medical authority or parental autonomy? J Med Ethics, 27: 104-109.

Nuffield Council on Bioethics. (2006). Critical care decision in fetal and neonatal medicine: ethical issues. First ed. London: Nuffield Council on Bioethics.

Office for National Statistics (ONS). (2011). Childhood, Infant and Perinatal Mortality in England and Wales. London: ONS.

Orfali, K. (2004). Parental role in medical decision-making: fact or fiction? A comparative study of ethical dilemmas in French and American neonatal intensive care units. Social Science \& Medicine, 58 (10): 2009-2022.

Pietrolongo, E., Giordano, A., Kleinefeld, M., Confalonieri, P., Lugaresi, A., Tortorella, C., Pugliatti, M., Radice, D., Goss, C., Heesen, C. \& Solari, A. (2013). Decision-making in multiple sclerosis consultations in Italy: third observer and patient assessments. PLoS One, 8, e60721.

Pilnick, A. (2008). 'It's something for you both to think about': choice and decision making in nuchal translucency screening for Down's syndrome, Sociology of Health \& Illness, 30 (4):511-530. doi: 10.1111/j.1467-9566.2007.01071.x

POPPY Steering Group. (2009). Family-centred care in neonatal units. A summary of research results and recommendations from the POPPY project. London: NCT. 
Potter, J. (1996). Representing reality: Discourse, rhetoric and social construction. London: Sage.

Quirk, A., Chaplin, R., Lelliott, P. \& Seale, C. (2012). How pressure is applied in shared decisions about antipsychotic medication: A conversation analytic study of psychiatric outpatient consultations. Sociology of Health \& Illness, 34: 95-113. DOI: 10.1111/j.1467-9566.2011.01363.x.

Roter, D. L., Larson, S., Fischer, G. S., Arnold, R. M. \& Tulsky, J. A. (2000). Experts practice what they preach: A descriptive study of best and normative practices in endof-life discussions. Arch Intern Med, 160: 3477-3485.

Royal College of Paediatrics and Child Health (RCPCH). (2004). Withholding or withdrawing life sustaining treatment in children: A framework for practice. Second edition. London: RCPCH.

Sacks, H., Schegloff, E. A. \& Jefferson, G. (1974). Simplest Systematics for Organization of Turn-Taking for Conversation. Language, 50: 696-735.

Silverman, D. (1997). Discourses of Counseling: HIV Counseling as Social Interaction. London: Sage.

Stivers, T. (2005). Non-antibiotic treatment recommendations: delivery formats and implications for parent resistance. Social Science \& Medicine, 60: 949-964.

Stokoe, E. (2010). “Have You Been Married, or ...?”: Eliciting and Accounting for Relationship Histories in Speed-Dating Interaction. Research on Language and Social Interaction, 43 (3): 260-282.

Stokoe, E. (2013). The (in)authenticity of simulated talk: Comparing role-played and actual conversation and the implications for communication training. Research on Language and Social Interaction, 46 (2): 1-21. DOI: 10.1080/08351813.2013.780341. 
Toerien, M., Shaw, R. \& Markus, R. (2013). Initiating decision-making in neurology consultations: 'Recommending' versus 'option-listing' and the implications for medical authority. Sociology of Health \& Illness, 35 (6): 873-890.

Vermeulen, E. (2004). Dealing with doubt: Making decisions in a neonatal ward in The Netherlands. Social Science \& Medicine, 59 (10): 2071-2085.

Whalen, J., Zimmerman, D.H., Whalen, M.R. (1988). When Words Fail: A Single Case Analysis. Social Problems 35(4): 335-362.

Wilkinson, D. (2013). Death or Disability?: The 'Carmentis Machine' and Decision-making for Critically Ill Children. Oxford University Press. 